Revue des patrimoines

\title{
Sacrifice subi ou sauvetage organisé. Le sort des archives en France durant la Grande Guerre, d'après le fonds de la direction ministérielle des Archives
}

\author{
Isabelle Chave
}

\section{(2) OpenEdition}

Journals

Édition électronique

URL : http://journals.openedition.org/insitu/10933

DOI : $10.4000 /$ insitu. 10933

ISSN : 1630-7305

Éditeur

Ministère de la culture

Référence électronique

Isabelle Chave, "

Sacrifice subi ou sauvetage organisé. Le sort des archives en France durant la Grande Guerre, d'après le fonds de la direction ministérielle des Archives », In Situ [En ligne], 23 | 2014, mis en ligne le 25 février 2014, consulté le 30 avril 2019. URL : http:// journals.openedition.org/insitu/10933 ; DOI : 10.4000/insitu.10933

Ce document a été généré automatiquement le 30 avril 2019

\section{c) (1)}

In Situ Revues des patrimoines est mis à disposition selon les termes de la licence Creative Commons Attribution - Pas d'Utilisation Commerciale - Pas de Modification 4.0 International. 


\title{
Sacrifice subi ou sauvetage organisé. Le sort des archives en France durant la Grande Guerre, d'après le fonds de la direction ministérielle des Archives
}

\author{
Isabelle Chave
}

Complémentaires des fonds locaux qui ont permis d'écrire déjà l'histoire de plusieurs services d'archives territoriaux durant la Grande Guerre, en particulier ceux situés dans le ressort de la zone Rouge ${ }^{1}$, les archives, conservées aux Archives nationales, du service administratif qui, depuis le XIXe siècle, exerce le contrôle central de l'État sur les dépôts d'archives départementales, communales et hospitalières et qui, en 1914, porte le nom de direction des Archives, au sein du ministère de l'Instruction publique, propose une source de premier intérêt pour envisager la question du sort des archives durant la Grande Guerre à l'échelon national ${ }^{2}$. Comment, malgré la chute des effectifs liée à la mobilisation et la complexité des conditions générales de fonctionnement, les services d'archives ontils maintenu leurs tâches fondamentales? Comment, dans la zone du front, les fonds d'archives, sur place ou par transfert, ont-ils été protégés de l'avancée des troupes ennemies? Comment, au sortir du conflit, dresser le bilan des pertes et intégrer la question du patrimoine archivistique dans les négociations des traités de paix de l'immédiat après-guerre? D'initiatives locales aux entreprises organisées à l'échelon national, la formidable mobilisation collective, sans précédent sans doute, d'un réseau professionnel à la tête duquel est placé Charles-Victor Langlois, directeur des Archives, se révèle de manière saisissante dans ce fonds d'archives encore peu connu. 


\section{Le réseau des archives face à la mobilisation et à l'entrée en guerre}

2 La mobilisation générale, décidée par décret du $1^{\mathrm{er}}$ août 1914 , est diffusée par voie d'affichage et de presse à partir du dimanche 2 août, premier jour de la mobilisation. Pour le réseau des services d'archives n'existait aucun plan préventif préconisant des mesures de protection pour le patrimoine archivistique. Si la Commission supérieure des archives se réunit à quatre reprises durant la guerre (19 juin 1915, 31 mai 1916, 23 juin 1917 et 18 juin 1918$)^{3}$, ses séances n'évoquent la gestion des archives en temps de guerre qu'à l'occasion de la séance de juin 1917 et ce n'est qu'en mars 1915 que sa section permanente se réunit, avec les inspecteurs généraux, "pour examiner le moyen de préserver les archives des risques de la guerre $»^{4}$.

\section{Une protection des fonds menée dans l'urgence}

3 Aux Archives nationales, dès la première semaine d'août 1914, un plan de campagne est dressé sous la direction d'un sous-officier des pompiers: les documents jugés les plus précieux (Trésor des Chartes, archives du Parlement de Paris, archives du Châtelet, documents du musée, etc.) sont mis à l'abri dans les caves de l'hôtel de Soubise, pour être protégés d'abord de l'avancée allemande, puis d'éventuels bombardements aériens ${ }^{5}$.

4 Aux Archives de la Seine, Marius Barroux fait déposer au coffre-fort les pièces les plus précieuses ; les registres et les cartons présentant un intérêt historique supérieur sont rassemblés au rez-de-chaussée, près de la porte du dépôt, pour pouvoir être descendus dans une cave, humide, très rapidement si nécessaire; de grands baquets pleins d'eau ont été installés par le service des pompiers de Paris, très sollicité durant tout le $\operatorname{conflit}^{6}$ (fig. $\mathbf{n}^{\circ} \mathbf{1}, \mathbf{n}^{\circ} \mathbf{2}, \mathbf{n}^{\circ} \mathbf{3}$ ). Comme dans bien des cas à l'échelon départemental, le service d'archives de la Seine devient, comme le note Barroux dans son rapport de 1914, un lieu-ressource, l'archiviste dispensant des conseils de protection des archives publiques de son secteur :

En septembre 1914, des communes ont eu recours, les unes au secrétariat général et aux archives, les autres à la direction des Archives départementales, au sujet des meilleures mesures à prendre pour la conservation de leurs archives, les règlements étant en effet muets sur ce point. J'ai adressé une note, le 3 , à l'archiviste de la Ville de Saint-Denis. Le maire de Bourg-la-Reine avait effectué, quai Henri-IV, provisoirement, un dépôt complémentaire, et celui de Joinville-lePont, fait apporter de même les registres d'état civil de la commune. [...] Les collections de l'administration générale de l'Assistance publique présentant une très grande importance, en raison notamment de leur ancienneté, $M$. le secrétaire général avait demandé, par note du 7 septembre 1914, quelles précautions étaient prises à leur égard. M. le directeur a répondu que les archives anciennes avaient été " déposées dans une cave sans issue et murée" [...]. Une note a été envoyée aussi à l'hôpital-hospice de Saint-Denis ${ }^{7}$.

Au cours du mois d'août 1914, relate Charles-Victor Langlois, directeur des Archives de France et directeur des Archives nationales, les archivistes départementaux en poste dans les chefs-lieux proches de la frontière allemande «ont déménagé dans les caves ou préparé, pour y être transférés à la première alerte, leurs documents les plus précieux. Ils ont fait connaitre [...] que les Archives départementales étaient prêtes à hospitaliser les 
parties les plus précieuses des archives des communes menacées. Dans le désordre d'événements si tragiques, presque aucun maire n'a profité, du reste, de ces offres ${ }^{8}$.»

\section{La mobilisation du personnel des services d'archives}

6 Dans une note du 10 avril 1915 au ministre de l'Instruction publique, Langlois déplore les effets immédiats de la mobilisation sur l'effectif des archivistes départementaux; dans trois services sur quatre, hors zone envahie, le responsable des Archives départementales a dû quitter son poste. Il témoigne d'une vigilance particulière pour les départements envahis ou occupés :

Dans le Nord, l'archiviste est resté à son poste [...]. Dans les Ardennes, l'archiviste a quitté son poste au commencement d'août, sur un ordre écrit du préfet, qui le couvre; aucune nouvelle depuis. Dans l'Aisne, même situation. [...] Il y a quatre départements, Meurthe-et-Moselle, Meuse, Oise et Somme, où les archivistes sont restés à leur poste comme non mobilisables. [...] Le cas des Vosges est semblable [...], si ce n'est que, ici, l'archiviste est mobilisé sur place [...]. Le Pas-de-Calais doit être mis à part : archiviste mobilisé dès le début, avant l'invasion'.

7 Cette situation sans précédent pousse la direction des Archives de France à encadrer, par circulaire du 20 novembre 1914, la réorganisation, voire la fermeture au public, des Archives départementales en cas de mobilisation importante du personnel ${ }^{10}$.

L'enquête sur les effectifs est réitérée le 27 septembre $1916^{11}$. Aulard, président de la Commission supérieure des archives, explique, lors de la séance du 31 mai 1916, que l'absence du personnel d'encadrement a précisément obligé à réunir la Commission moins souvent ${ }^{12}$.

9 À l'instar d'autres administrations publiques, les services d'archives subissent, tout au long du conflit, la perte progressive d'une partie de leur personnel. Les Archives nationales perdirent un archiviste (R. André-Michel), deux gardiens : Pilat, capitaine de chasseurs alpins, tué à la bataille de la Somme, en 1916, et Audoin, en 1917, des suites d'une blessure de guerre, enfin, deux autres gardiens (Dominici et Mouchès), disparus dès 1914 ${ }^{13}$. Les Archives de la Seine vivent une expérience assez semblable. En septembre 1914 sont mobilisés l'expéditionnaire principal (Laudner, adjudant) et un gardien de bureau (Verpot), suppléés par le brigadier des gardiens et le concierge. Le 22 septembre 1914, le concierge, mobilisé à son tour comme lieutenant de réserve, est remplacé par sa femme. Début 1915 meurt en Alsace le sous-archiviste, Henri Prost, sergent de réserve; le directeur du service assure les fonctions d'agent comptable, tandis qu'un autre agent (Farge) est mobilisé en mars. L'expéditionnaire principal et le gardien mobilisés en septembre 1914 meurent tous deux en 1916 ; le personnel ne compte plus alors que deux agents de service auxiliaires. En avril 1917 est tué le dernier expéditionnaire (Nicodémi, capitaine) du dépôt. Ce service aura donc connu le décès au front de deux collaborateurs et la mobilisation de deux employés et de quatre agents du personnel secondaire, dont l'activité a été palliée par la mise à disposition de quatre femmes et d'un instituteur ${ }^{14}$. Dans son ressort d'activité, Marius Barroux déplora aussi la mort de Frédéric Duval, responsable des archives de la Ville de Saint-Denis ${ }^{15}$. 
Figure 1

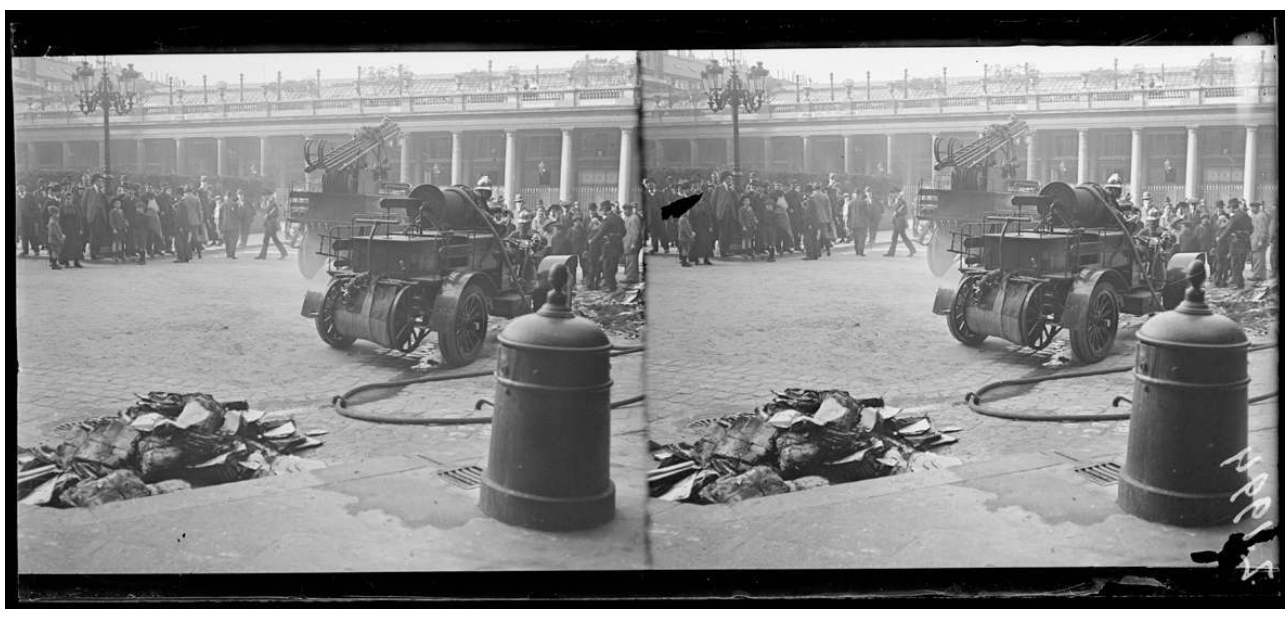

Paris : Incendie des archives de la Cour des comptes, le 24 avril 1916, au Palais-Royal. Les clichés sont de l'opérateur Fortin, probablement à proximité, dans les locaux du Service photographique et cinématographique des Armées.

(c) Ivry-sur-Seine, ECPAD, SPA 35 Z 1994.

Figure 2

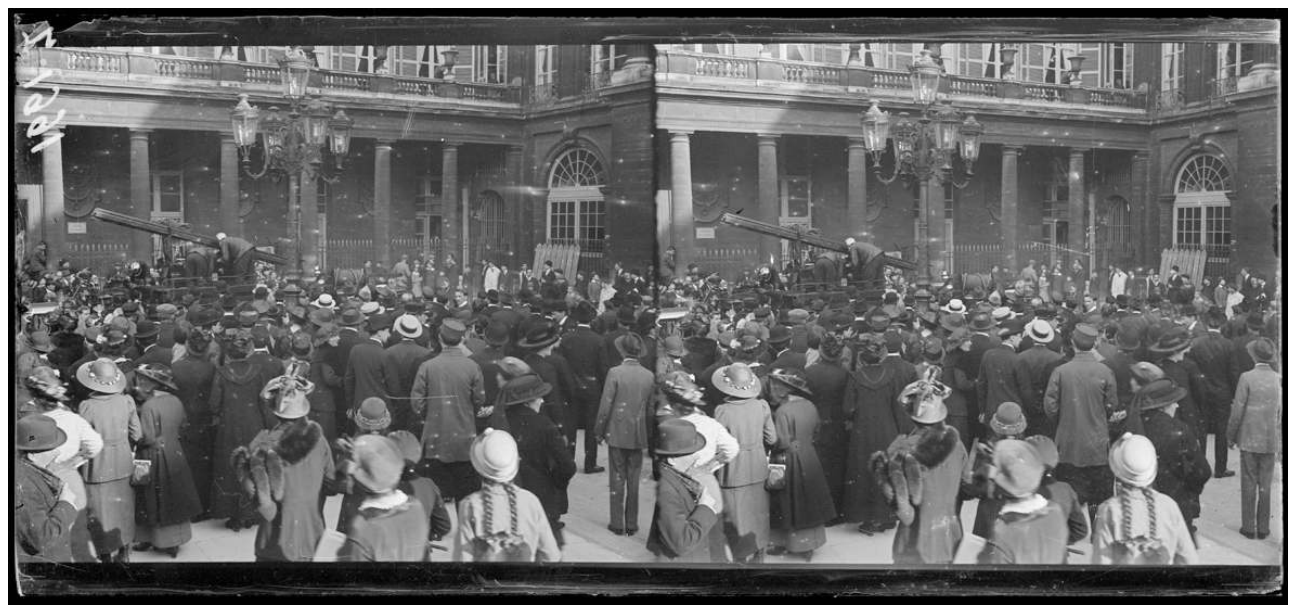

Paris : Incendie des archives de la Cour des comptes, le 24 avril 1916, au Palais-Royal. Les clichés sont de l'opérateur Fortin, probablement à proximité, dans les locaux du Service photographique et cinématographique des Armées.

(c) Ivry-sur-Seine, ECPAD, SPA 35 Z 1991. 
Figure 3

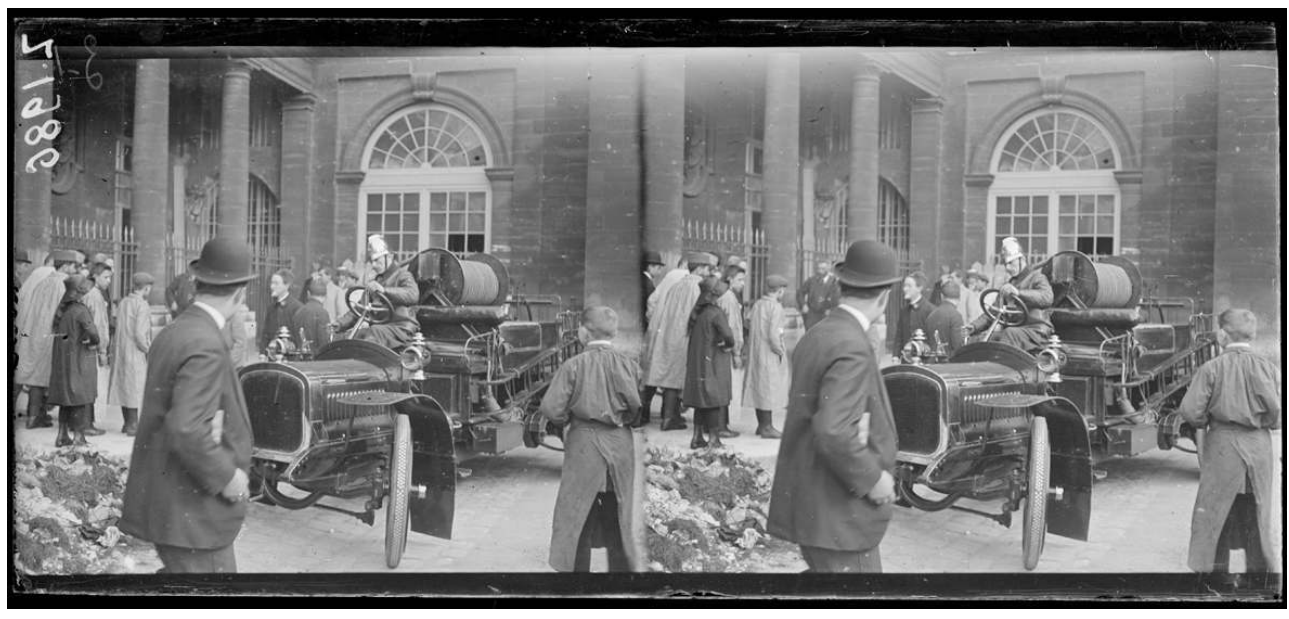

Paris : Incendie des archives de la Cour des comptes, le 24 avril 1916, au Palais-Royal. Les clichés sont de l'opérateur Fortin, probablement à proximité, dans les locaux du Service photographique et cinématographique des Armées.

(c) Ivry-sur-Seine, ECPAD, SPA 35 Z 1986.

À l'échelon territorial, en 1917, vingt archivistes départementaux étaient mobilisés au total, alors même, comme le rappelle Langlois dans son rapport de mai 1918, que «les nominations de fonctionnaires nouveaux sont suspendues, en principe, pendant la guerre $\aleph^{16}$. Quatre archivistes départementaux perdirent la vie durant la Grande Guerre ${ }^{17}$.

\section{Le fonctionnement des services d'archives en temps de guerre}

\section{L'adaptation des activités}

11 Dans la plupart des services d'archives français, les mesures exceptionnelles prises à l'entrée en guerre s'allègent dès 1915. Pour la Seine, Marius Barroux note ainsi que « les mairies de Bourg-la-Reine et de Joinville-le-Pont ont repris les documents déposés par elles au mois de septembre $1914{\aleph^{18}}^{18}$. Les dommages en début de guerre ont été limités, à l'exception de petits dépôts communaux situés sur la ligne de feu et surtout de Senlis, où les archives de la sous-préfecture et des notaires ayant leur résidence dans la ville ont disparu dans les flammes, incitant même Charles-Victor Langlois à écrire, le 25 mai 1915 : « de nos richesses nationales, les archives sont peut-être celles qui ont le moins souffert » 19 .

12 Un fonctionnement dégradé s'est instauré un peu partout, adapté à la réduction des effectifs du personnel mobilisé. Aux Archives nationales, la salle de lecture resta ouverte aux lecteurs durant presque toute la guerre, mais la salle des inventaires et le musée furent fermés durant près de cinq ans ${ }^{20}$. Aux Archives de la Seine, Marius Barroux, le $1^{\text {er }}$ août 1914, fait renvoyer au greffe du tribunal de première instance de la Seine toutes les demandes d'actes de l'état civil sur timbre, avant de fermer les bureaux du rez-dechaussée de son service, quelques jours plus tard, pour que la surveillance soit moins compromise par le faible effectif de personnel restant, en déplorant que «le travail de classement et d'inventaire, pourtant caractéristique d'un dépôt d'archives, [se soit] 
trouvé arrêté depuis quatorze mois » ; en 1915 encore, « c'est à peine si le personnel suffit à classer les documents entrés $»^{21}$. En mai 1917, les dépôts départementaux fermés aux recherches du public du fait de l'absence de l'archiviste mobilisé sont au nombre de vingt, contre dix-sept au printemps 1916; les services d'archives de la Manche, des Deux-Sèvres et de l'Yonne ont, en effet, été contraints de fermer, mais « aucun des départements du front n'est dans ce cas; heureusement, car la présence de l'archiviste y est indispensable », précise Charles-Victor Langlois, dans son rapport annuel pour $1916^{22}$.

\section{Exemple de l'évolution de l'activité des Archives de la Seine, de 1913 à 1919}

13 [d'après Marius Barroux, "Rapports annuels de l'archiviste [de la Seine]. Exercices 1913-1914 et 1914-1915 ", Tirés à part de la Bibliothèque de l'École des chartes, Paris, 1919, p. 42-43].

\begin{tabular}{|c|c|c|c|c|c|c|}
\hline & 1913 & $1914-1915$ & 1916 & 1917 & 1918 & 1919 \\
\hline $\begin{array}{l}\text { Correspondance à l'arrivée (nombre } \\
d^{\prime} \text { " affaires ») }\end{array}$ & 10833 & & 8624 & 7637 & 6098 & 9139 \\
\hline $\begin{array}{l}\text { Versements (nombre de registres ou } \\
\text { cartons) }\end{array}$ & 7759 & 8357 & 2185 & 9059 & 3139 & 4503 \\
\hline Communications avec sortie du dépôt & 365 & & 122 & 139 & 94 & 151 \\
\hline $\begin{array}{l}\text { Délivrances de rôles de documents } \\
\text { administratifs }\end{array}$ & 896 & & 279 & 423 & 373 & 379 \\
\hline Suppressions de papiers (en kg) & $\begin{array}{l}170 \\
880\end{array}$ & & $\begin{array}{l}115 \\
710\end{array}$ & $\begin{array}{l}119 \\
650\end{array}$ & $\begin{array}{l}126 \\
800\end{array}$ & $\begin{array}{l}188 \\
710\end{array}$ \\
\hline Inscriptions d'actes enregistrés & & & & & 4311 & 6087 \\
\hline Délivrances de bulletins d'état civil & & & & & 347 & 6003 \\
\hline $\begin{array}{l}\text { Transmission d'actes concernant des } \\
\text { étrangers }\end{array}$ & 2276 & & 2014 & 2397 & 3793 & 3658 \\
\hline $\begin{array}{l}\text { Nombre de recherches dans les tables } \\
\text { décennales }\end{array}$ & & & & 2843 & 1972 & 1658 \\
\hline Nombre d'extraits à transcrire & 1220 & & 3400 & 1951 & 1493 & 950 \\
\hline $\begin{array}{l}\text { Nombre de mentions de mariage à } \\
\text { transcrire }\end{array}$ & 558 & & 285 & 225 & 232 & 245 \\
\hline
\end{tabular}

Pour autant, les services doivent répondre à des besoins d'un type nouveau, directement nés de la guerre, tels que la réponse à l'afflux de demandes de preuves de certificats d'exemption du service militaire, de tirage au sort ou d'inscription sur les listes de la Garde nationale ${ }^{23}$, ou encore la transmission aux mairies d'actes d'état civil pour transcription sur les registes de décès ou pour insertion de la mention « Mort pour la France $»^{24}$. 


\section{La protection des documents d'archives face à la lutte contre la crise des matières premières}

La disette de matières premières pour la fabrication du papier a fait penser, dès le début de la guerre, qu'il serait pertinent de procéder à la vente des «papiers inutiles». Selon le rapport des Archives nationales pour mai 1916-mai 1917, avec l'appui des pouvoirs publics, « en avril [1916], un groupement économique, constitué pour rechercher les moyens de remédier à la crise sévissant sur la fabrication du papier faute de matières premières, a organisé une propagande en vue de procéder à la récolte de tous les vieux papiers, à l'exclusion des papiers dits de chiffonnier ${ }^{25}$. Dès le 27 avril 1916, le ministre de l'Instruction publique donna des instructions précises aux préfets et aux recteurs de ne pas y englober les documents d'archives. Le risque réapparaît, le 5 juin 1916, alors que, dans Le Temps, paraît une note soulignant l'intérêt de la vente des archives inutiles des services de l'État et enjoignant qu'elles « soient le cas échéant [...] remises au domaine aux fins d'aliénation $»^{26}$, sans évoquer là le rôle de l'administration des Archives. Dès juinjuillet 1916, en riposte, le ministre de l'Instruction publique adressa aux chefs des divers départements ministériels une série de dépêches contraires pour réexpliquer la démarche, appuyée sur le décret du 12 janvier 1898, de transfert des archives inutiles aux Archives nationales ou départementales, chargés de l'évaluation (« l'examen et le triage $»)$.

\section{La collecte de témoignages écrits et imprimés du temps de la guerre}

\section{Les « fiches d'histoire locale » des instituteurs}

Le 18 septembre 1914, le ministère de l'Instruction publique donne des instructions pour inviter les instituteurs à prendre des notes sur les événements, de manière à former " une sorte de répertoire d'histoire locale", en deux exemplaires, pendant la guerre ${ }^{27}$. Le 27 décembre de la même année, une circulaire ministérielle aux préfets, également diffusée auprès du réseau de la direction de l'Enseignement, grâce au Bulletin départemental de l'Enseignement primaire, prévoit qu'un double de ces dossiers, ou « fiches d'histoire locale », devait être déposé aux Archives départementales, dans la série $\mathrm{R}^{28}$.

\section{Les affiches de guerre}

17 Le 18 janvier 1915, la direction des Archives étend à tout le réseau des services d'archives la démarche de collecte spontanée des affiches de guerre, lancée à Paris :

Les Archives nationales ont entrepris de recueillir, pour les conserver en collection spéciale, les affiches placardées sur les murs en vue de la présente guerre, depuis le premier jour de la mobilisation jusqu'à la cessation des hostilités. En vue d'associer les Archives départementales à cette œuvre d'utilité nationale, je vous prierai de prendre les mesures qui vous paraîtront les plus propres pour faciliter la centralisation à la préffecture de toutes les affiches de guerre, générales ou locales, publiques ou privées, qui ont été placardées ou qui le seront dans l'étendue du territoire soumis à votre autorité ${ }^{29}$.

Cette mesure fut, en effet, appliquée dans plusieurs services d'archives départementales ${ }^{30}$. 


\section{L'alimentation des collections du musée de la Guerre}

Formé par l'industriel parisien Henri Leblanc, et son épouse Louise, à partir de la documentation qu'ils compilèrent dès 1914, le musée de la Guerre diffuse, en 1916, des invitations à enrichir ses collections d'exemplaires de documents imprimés produits par la préfecture de Paris ou les services en dépendant, faisant parfois obstacle à la politique de collecte des Archives de la Seine, qui, à la fin du conflit, sentent la nécessité de renforcer leur visibilité auprès des mairies des arrondissements de Paris ${ }^{31}$.

\section{Les archives dans les tensions politico-militaires de 1914,1917 et 1918 : entre sauvegarde sur place et évacuation}

\section{La réaction professionnelle à l'invasion de l'automne-hiver 1914}

20 Il est vraisemblable que l'expérience vécue par le directeur des Archives de France, en mission dans le Pas-de-Calais en novembre 1914, l'a sensibilisé à la situation des dépôts d'archives des zones frontières. À Arras, en novembre 1914, l'archiviste départemental, Flament, étant mobilisé, Charles-Victor Langlois était venu, au palais abbatial Saint-Vaast, donner en direct ses instructions de protection des Archives départementales, y revenant encore, sur dépêche du ministre de l'Instruction publique du 8 juillet 1915, pour évacuer les fonds placés dans les sous-sols du palais ${ }^{32}$.

21 La direction des Archives ressent, le 10 juin 1915, le besoin de procéder à un premier recensement des mesures prises dans les départements du front depuis l'invasion d'août 1914. Les archivistes départementaux de l'Aube, de la Haute-Marne et de Seine-etMarne et, dès que la partie occupée de leur ressort aura été évacuée, ceux de la Marne, de Meurthe-et-Moselle, de la Meuse, de l'Oise, du Pas-de-Calais, de la Somme et des Vosges doivent dresser la nomenclature précise des dépôts qui, malgré les précautions mises en place, ont été endommagés et « recueillir les noms des fonctionnaires et des citoyens qui se sont employés [...] à sauver des archives en danger $»^{33}$.

Cette enquête se double de l'envoi, durant l'été 1915, en tournée auprès des préfets et des sous-préfets de la zone des Armées et de la zone réservée, de l'inspecteur général Camille Bloch, futur directeur de la Bibliothèque-musée de la guerre, installée dans le pavillon de la Reine au château de Vincennes en 1924. Parcourant treize départements (Aisne, Aube, Haute-Marne, Marne, Meuse, Meurthe-et-Moselle, Nord, Oise, Pas-de-Calais, Seine-etMarne, Seine-et-Oise, Somme et Vosges), il recueille tous les renseignements possibles sur les mesures de protection sur place et les dégradations de l'ennemi auprès des préfets, sous-préfets, maires des principales communes et archivistes départementaux, donnant lieu à une importante note manuscrite de 33 pages, remise le 12 août 1915 au directeur des Archives et au ministre de l'Instruction publique ${ }^{34}$.

Cette circulaire du 10 juin 1915 est complétée, le 24 août 1915, d'une autre circulaire aux préfets, pour les inviter à communiquer aux maires les premières précautions à prendre : " en cas de danger présent ou seulement possible, placer dans des caves, à l'abri de l'humidité, les documents les plus précieux ou même les expédier à l'arrière, au dépôt des archives de la sous-préfecture ou du département ${ }^{35} »$. 
usieurs démarches plus concrètes sont prises en application de ces dispositions générales : le 31 août 1915, l'archiviste départemental de l'Aisne est invité à envoyer aux Archives nationales les archives hospitalières anciennes de Soissons; le 8 janvier 1916, le préfet de Meurthe-et-Moselle est invité à évacuer les archives départementales en cas de bombardement intense ou incendiaire, demande réitérée le 18 janvier 1917 ; enfin, Langlois obtient, le 12 février 1917, que l'archiviste départemental de la Marne évacue vers Châlons le fonds historique du greffe du tribunal de Reims ${ }^{36}$.

\section{L'année 1917 ou la réaction aux replis successifs des Allemands}

$\mathrm{Au}$ lendemain du premier repli des Allemands, le 24 mars 1917, le ministre de l'Instruction publique, à l'instigation de Langlois, invite les préfets des deux départements libérés en totalité (Oise et Somme) et ceux des deux départements libérés en partie (Aisne, Pas-de-Calais) à prendre immédiatement, avec l'autorité militaire, les mesures nécessaires pour recueillir et mettre à l'abri les documents trouvés dans les ruines des mairies détruites par l'ennemi en retraite ; les archivistes départementaux, « inspecteurs des archives municipales de leur ressort ", sont chargés de cette mission, tandis qu'en Alsace, le directeur des Archives nationales pouvait compter sur deux représentants, Schmidt, archiviste, et Gaudillère, commis, veillant à la conservation des dépôts dans les localités occupées par les Français ${ }^{37}$. Dans ce contexte, Langlois parvient aussi, en juin 1917, à convaincre le maire de Reims d'évacuer Paris les archives municipales, qu'il avait tenu à conserver jusque-là dans la ville ${ }^{38}$.

Dans le cadre d'une mission, en octobre 1917, le directeur des Archives de France parcourt la région du Pas-de-Calais et du Nord, tandis que l'inspecteur général des Archives, Vidier, fait de même pour la région de l'Est ${ }^{39}$. Le 17 octobre, Langlois propose d'évacuer sur l'arrière les archives communales de Calais, si nécessaire, et, le 22 octobre, offre au préfet du Nord l'aide des Archives de France, si l'évacuation des archives communales de Dunkerque s'impose ${ }^{40}$. En Meurthe-et-Moselle, quarante-et-une communes du front confièrent leurs archives au dépôt départemental ${ }^{41}$. Lors de la séance de la Commission supérieure des Archives du 18 juin 1918, Langlois peut ainsi faire le bilan des précautions prises, depuis juin 1917, pour préserver les archives dans les départements du Nord, du Pas-de-Calais, de la Somme, de l'Oise, de l'Aisne, de la Marne, de la Meuse, de Meurthe-et-Moselle et des Vosges ${ }^{42}$.

bien souvent, l'évacuation des archives communales a été opérée par l'ennemi luimême (fig. $\mathbf{n}^{\circ} \mathbf{4}$ ). Ainsi, dans le Pas-de-Calais, les archives de vingt-trois communes ont été évacuées par les Allemands vers Valenciennes, le 3 mars 1917, celles de Billy-Montigny, vers Wavre (Belgique), celles de Bois-Bernard, vers Pesseux (Belgique), puis au consulat d'Espagne ; celles d'Hermiers, vers Taisnières-sur-Hon, celles de Noyelles-sous-Lens, vers Hénin-Liétard ${ }^{43}$. Le cas est analogue en Meurthe-et-Moselle : les Allemands transportèrent à Metz les archives de trente-quatre communes, qui n'en revinrent qu'entre mars et juillet $1919^{44}$. 


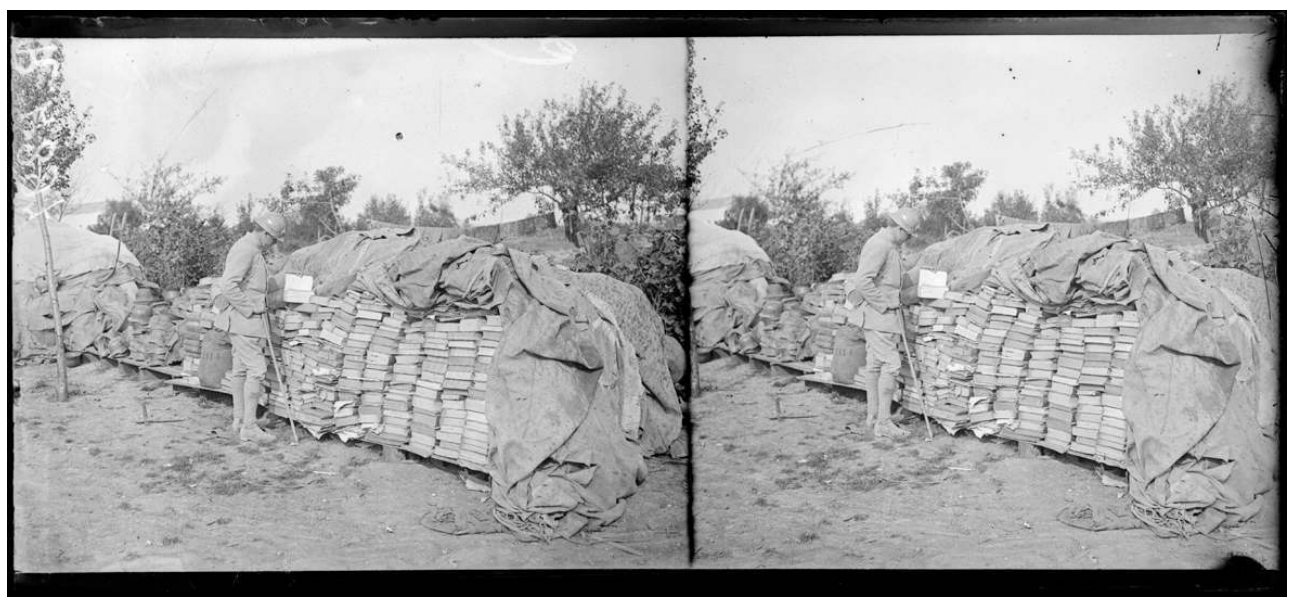

Évacuation allemande des archives municipales de Montdidier (Somme). À La Boissière (Somme), en août 1918, au sein d'un dépôt allemand de récupération de matériels, sont photographiées les archives de Montdidier, simplement déposées sur palettes et bâchées.

(c) Ivry-sur-Seine, ECPAD, SPA 144 R 4897.

En toute fin d'année, le $1^{\text {er }}$ décembre 1917, à l'exemple des conditions de libération de la région de Noyon et de repli des Allemands, un an auparavant, le ministre de l'Instruction publique demande, pour le compte de la direction des Archives, au cabinet civil du ministre de la Guerre qu'il soit adjoint aux prévôtés d'armée et aux missions françaises près des armées anglaises, dans chaque armée avançant en pays reconquis, un archiviste de carrière, mobilisé, qui s'occuperait, en technicien, de la sécurité des archives et des papiers publics à sauvegarder ${ }^{45}$. Le projet, au vrai, avait déjà été présenté au cabinet du ministre de la Guerre, le $1^{\text {er }}$ août 1917, sans aboutir, malgré la liste fournie d'archivistes mobilisés - cinq ou six archivistes professionnels, alors soldats ou sous-officiers susceptibles d'exercer ces fonctions ${ }^{46}$. Après avoir accepté, le ministre de la Guerre se rétracte et refuse le 8 janvier 1918, reconsidérant l'évolution de la situation militaire. Le cabinet civil renvoie aux dispositions déjà prises par le ministère de la Guerre par instruction du 2 avril $1917^{47}$.

\section{Le printemps 1918 ou le renforcement des mesures d'urgence}

Les premiers indices de l'aggravation de la situation concernent, début 1918, la Meurtheet-Moselle et les Vosges : le 26 février, Langlois invite le préfet des Vosges à évacuer les Archives départementales et, le 28 février, sur demande de l'archiviste Vidier, les registres anciens du greffe de la cour d'appel de Nancy sont expédiés aux Archives nationales ${ }^{48}$.

La situation s'accélère ensuite au mois d'avril 1918 (voir aussi l'annexe I). Le 10 avril, Langlois indique au préfet de Dunkerque la nécessité d'évacuer; le 15 avril, l'archiviste départemental de l'Oise est invité à préparer l'évacuation de ses archives et des archives communales de Beauvais, ainsi que des archives municipales et hospitalières de Compiègne ; le 19 avril, un télégramme du cabinet du ministre de l'Instruction publique demande au préfet de la Marne si l'évacuation est utile, tandis que l'archiviste de la Somme est invité à prendre ses dispositions pour évacuer le dépôt des archives départementales, ainsi que les archives communales et hospitalières d'Amiens (fig. $\mathbf{n}^{\circ} \mathbf{5}, \mathbf{n}$ 
$\left.{ }^{\circ} \mathbf{6}, \mathbf{n}^{\circ} 7, \mathbf{n}^{\circ} \mathbf{8}\right)$. Les 20 ou 22 avril, des instructions d'évacuation sont adressées au souspréfet de Compiègne ; le 26 avril, Langlois confirme au préfet de la Marne l'instruction d'évacuer les archives départementales et, le 27 avril, le préfet de la Somme est informé que l'évacuation aura lieu prochainement par les soins de l'autorité militaire ${ }^{49}$. Dans la Marne, la brusque irruption allemande de 1918 poussa de même à évacuer massivement les archives des communes, soit dans le sud du département, soit encore à Lyon et à Nîmes ${ }^{50}$. Ces lieux d'évacuation étaient le Rhône et l'Hérault. Certains services d'archives départementales n'ont plus même le temps d'organiser l'évacuation : les archives du Nord restent sur place à Lille; celles de l'Aisne sont évacuées de Laon à Valenciennes, les Allemands ayant transformé le dépôt départemental en caserne.

Figure 5

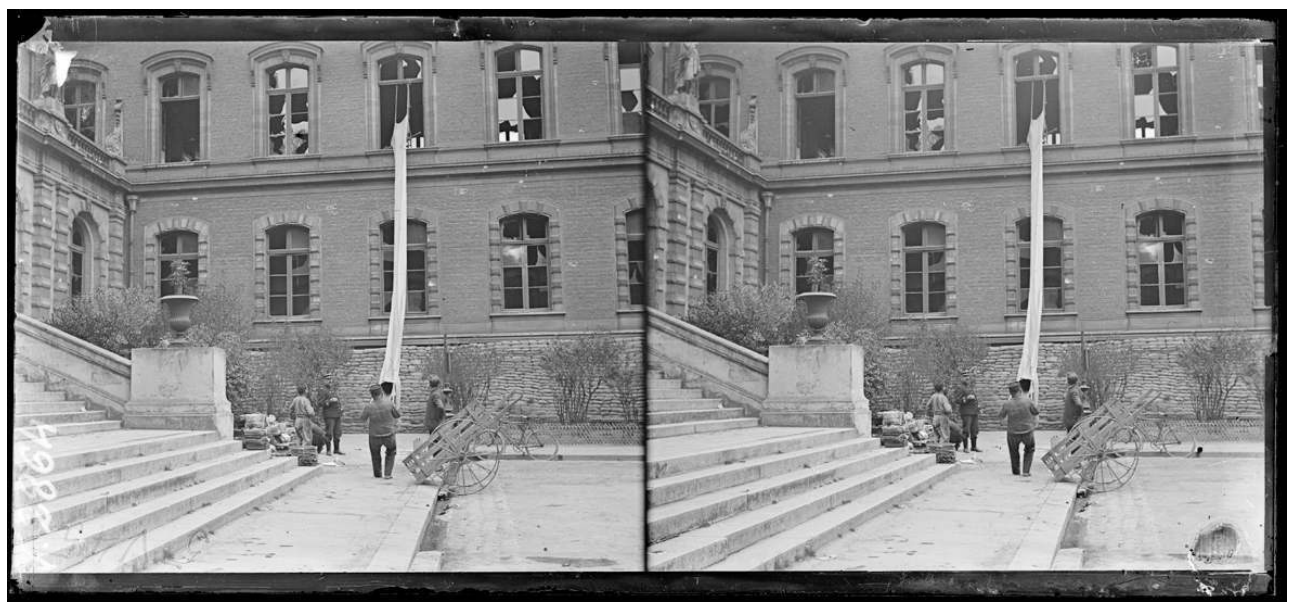

Évacuation des archives de la mairie d'Amiens (Somme). Place Gambetta, le 22 juin 1918, l'hôtel du Périgord est détruit, comme de nombreuses habitations rues Lourendeau, Cozette, Latour ou rue des Jacobins, tandis que les archives de la mairie sont évacuées, par crainte de destruction lors d'un bombardement.

(c) Ivry-sur-Seine, ECPAD, réf. SPA 92 V 2864.

Figure 6

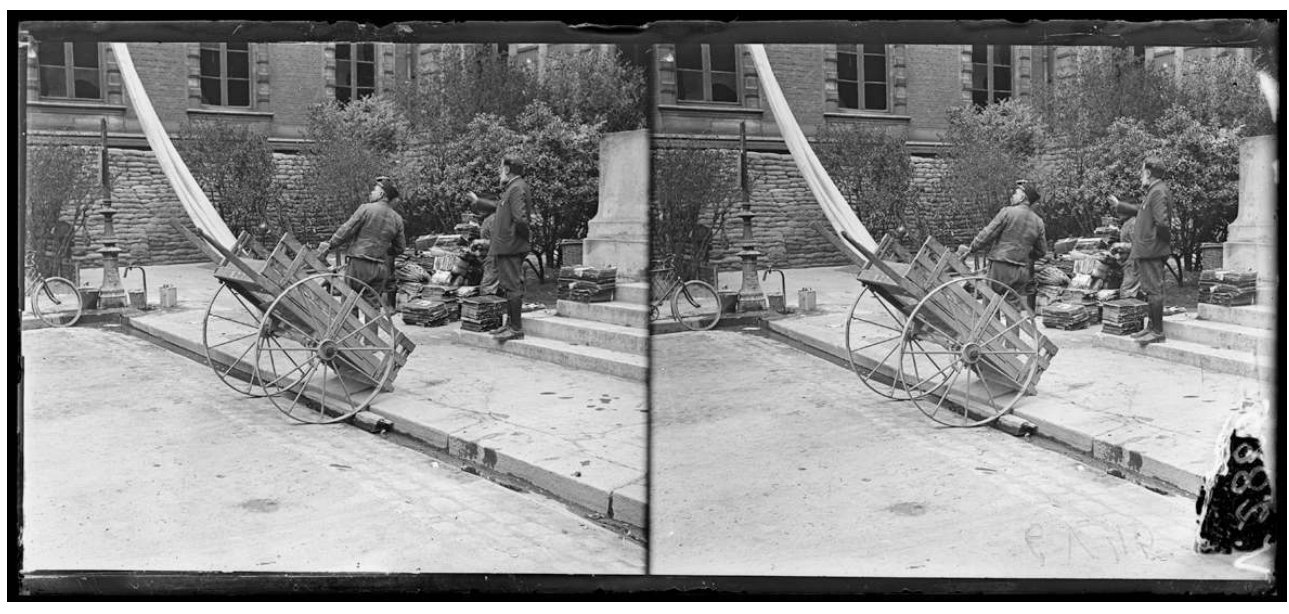

Évacuation des archives de la mairie d'Amiens (Somme). Place Gambetta, le 22 juin 1918, l'hôtel du Périgord est détruit, comme de nombreuses habitations rues Lourendeau, Cozette, Latour ou rue des Jacobins, tandis que les archives de la mairie sont évacuées, par crainte de destruction lors d'un bombardement.

(c) Ivry-sur-Seine, ECPAD, réf. SPA 92 V 2865. 
Figure 7

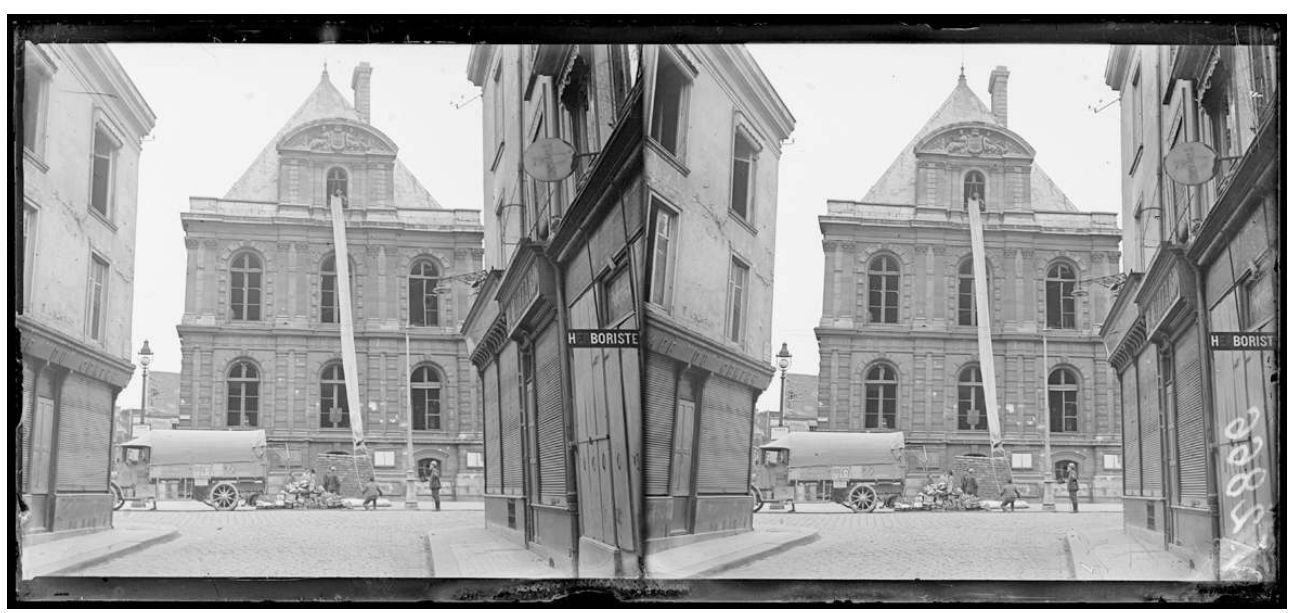

Évacuation des archives de la mairie d'Amiens (Somme). Place Gambetta, le 22 juin 1918, l'hôtel du Périgord est détruit, comme de nombreuses habitations rues Lourendeau, Cozette, Latour ou rue des Jacobins, tandis que les archives de la mairie sont évacuées, par crainte de destruction lors d'un bombardement.

(c) Ivry-sur-Seine, ECPAD, réf. SPA 92 V 2866.

\section{Figure 8}

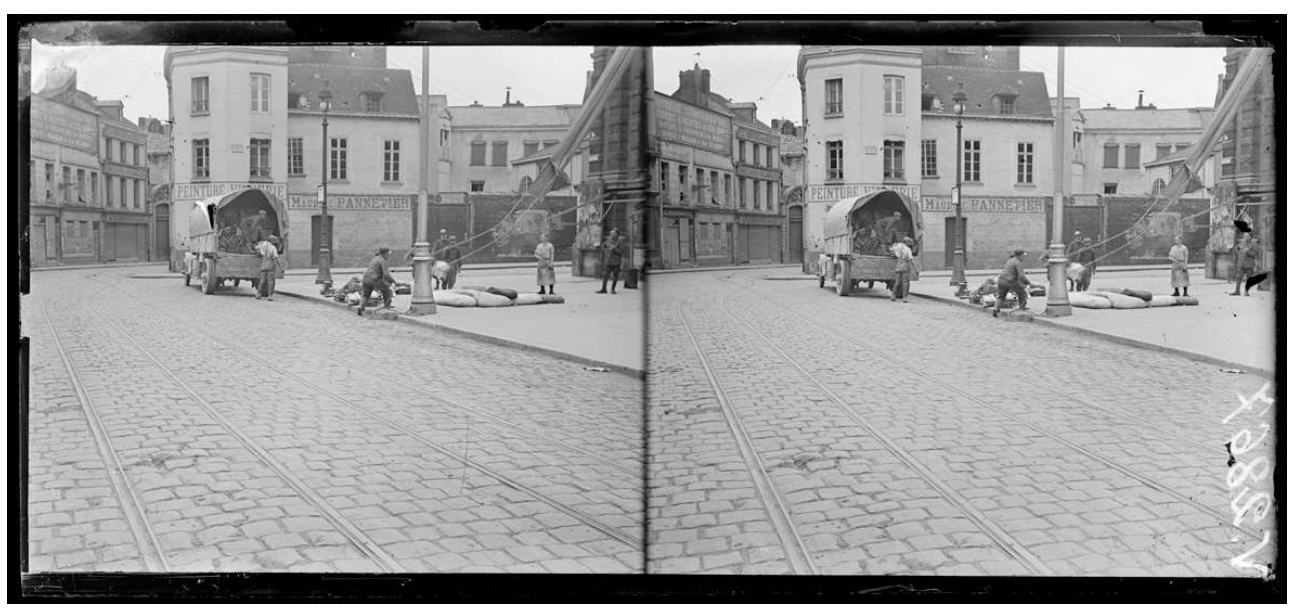

Évacuation des archives de la mairie d'Amiens (Somme). Place Gambetta, le 22 juin 1918, l'hôtel du Périgord est détruit, comme de nombreuses habitations rues Lourendeau, Cozette, Latour ou rue des Jacobins, tandis que les archives de la mairie sont évacuées, par crainte de destruction lors d'un bombardement.

(c) Ivry-sur-Seine, ECPAD, réf. SPA 92 V 2867.

31 Ainsi que Langlois a pu en dresser le panorama dans son rapport de mai 1919,

du printemps à l'automne 1918, des mesures de précaution ont dû être prises dans un grand nombre de dépôts qui avaient paru être en sécurité jusque-là, notamment dans les départements de la Somme, de l'Oise, de la Marne, de la Meuse, de Meurthe-et-Moselle, etc. Quantité de documents ont voyagé à cette occasion d'un bout à l'autre de la France. Il y a eu un moment où les Archives départementales de la Meuse étaient en partie hospitalisées à Bordeaux ; celles de l'Oise, à Nîmes ; celles de la Somme, à Rouen et à Lyon; celles de Meurthe-et-Moselle, à Troyes ; celles des Vosges, à Montpellier (fig. $\left.\mathbf{n}^{\circ} \mathbf{9}, \mathbf{n}^{\circ} \mathbf{1 0}, \mathbf{n}^{\circ} \mathbf{1 1}, \mathbf{n}^{\circ} \mathbf{1 2}\right) ;$ celles de la Marne, à Lyon et à Nîmes. Les archives municipales de Saint-Omer ont été dirigées sur Bordeaux; 
celles de Dunkerque, sur Le Mans; celles de Beauvais, sur Châteauroux; celles d'Hazebrouck, dans l'Orne ; celles de l'hôpital de Compiègne, à Aire-sur-l'Adour ; celles des communes du front de l'Aisne, à Chartres, etc. ${ }^{51}$.

Lors de la séance du 18 juin 1918 de la Commission supérieure des Archives, signalant en particulier le dévouement du commandant Welter, du cabinet civil du ministre de la Guerre, qu'il faut créditer en partie de la sauvegarde des Archives de la Somme, le directeur des Archives nationales énumère déjà les centres de repli choisis à l'arrière pour recevoir les dépôts évacués, en particulier les Archives départementales de la Gironde, de la Sarthe, du Rhône, du Gard et de l'Hérault ${ }^{52}$.

\section{État des archives évacuées des départements du front en 1918 et leur destination}

33 [d'après une note manuscrite de la direction des Archives, [1918-1919], Arch. nat., AB $\mathrm{XXXI} / 356]$.

\begin{tabular}{|c|c|}
\hline Fonds d'archives & Lieu d'évacuation \\
\hline \multicolumn{2}{|l|}{ Aisne } \\
\hline $\begin{array}{l}\text { Sous-préfecture et communes diverses } \\
\text { de l'arrondissement de Château-Thierry }\end{array}$ & $\begin{array}{l}\text { Péniche sur Orléans, destination modifiée en cours } \\
\text { de route, sans doute Chartres [biffé et corrigé en : et Le } \\
\text { Mans]. }\end{array}$ \\
\hline Soissons, archives hospitalières & Oulchy-le-Château \\
\hline Saint-Pierre-Aigle, archives communales & Saint-Ouen-l'Aumône \\
\hline $\begin{array}{l}\text { Archives communales diverses de la } \\
\text { zone de combat }\end{array}$ & Archives nationales \\
\hline \multicolumn{2}{|l|}{ Marne } \\
\hline $\begin{array}{l}\text { Archives départementales, } \\
\text { enregistrement et domaines }\end{array}$ & Lyon, Archives départementales \\
\hline Châlons, archives communales & Troyes et Lyon, Archives départementales \\
\hline Vitry-le-François, archives communales & Le Mans, Archives départementales \\
\hline Reims, archives communales & Archives nationales \\
\hline Archives communales diverses & Chartres, Archives départementales \\
\hline \multicolumn{2}{|l|}{ Meurthe-et-Moselle } \\
\hline Archives départementales & Troyes, Archives départementales \\
\hline Cour souveraine de Lorraine & Archives nationales \\
\hline Nancy, archives communales & Lyon, Archives départementales \\
\hline \multicolumn{2}{|l|}{ Meuse } \\
\hline Archives départementales & Bordeaux, Archives départementales \\
\hline $\begin{array}{l}\text { Verdun, archives communales et } \\
\text { hospitalières anciennes }\end{array}$ & Riom \\
\hline Verdun, état civil du greffe & Dijon, cour d'appel \\
\hline
\end{tabular}




\begin{tabular}{|c|c|}
\hline $\begin{array}{l}\text { Communes diverses de la zone de } \\
\text { combat }\end{array}$ & Archives nationales \\
\hline \multicolumn{2}{|l|}{ Nord } \\
\hline Enregistrement et hypothèques & Évreux et Louviers \\
\hline Dunkerque, marine & Paris, archives du ministère de la Marine \\
\hline Dunkerque, archives communales & Le Mans, Archives départementales \\
\hline Hazebrouck, archives communales & $\begin{array}{l}\text { Le Mans, Archives départementales [biffé et corrigé en } \\
\text { : Laigle (Orne)] }\end{array}$ \\
\hline \multicolumn{2}{|l|}{ Oise } \\
\hline Archives départementales & $\begin{array}{l}\text { Nîmes et Le Mans, Archives départementales [Le } \\
\text { Mans, biffé] }\end{array}$ \\
\hline Compiègne, archives communales & Enghien-les-Bains \\
\hline Compiègne, archives hospitalières & Aire-sur-l'Adour \\
\hline $\begin{array}{l}\text { Archives communales diverses de la } \\
\text { zone de combat }\end{array}$ & Archives nationales \\
\hline \multicolumn{2}{|l|}{ Pas-de-Calais } \\
\hline Archives départementales & Archives nationales et Boulogne \\
\hline Arras, archives communales & Archives nationales \\
\hline Saint-Omer, archives communales & Bordeaux \\
\hline $\begin{array}{l}\text { Archives communales diverses de } \\
\text { l'arrondissement de Saint-Omer }\end{array}$ & Le Mans \\
\hline $\begin{array}{l}\text { Archives communales de la zone de } \\
\text { combat }\end{array}$ & Archives nationales \\
\hline \multicolumn{2}{|l|}{ Somme } \\
\hline Archives départementales & Lyon et Rouen, Archives départementales \\
\hline $\begin{array}{l}\text { Archives communales de la zone de } \\
\text { combat }\end{array}$ & Archives nationales \\
\hline \multicolumn{2}{|l|}{ Vosges } \\
\hline Archives départementales & Montpellier, Archives départementales \\
\hline Épinal, archives communales & Montpellier, Archives départementales \\
\hline Saint-Dié, archives communales & Montpellier, Archives départementales \\
\hline
\end{tabular}


Figure 9

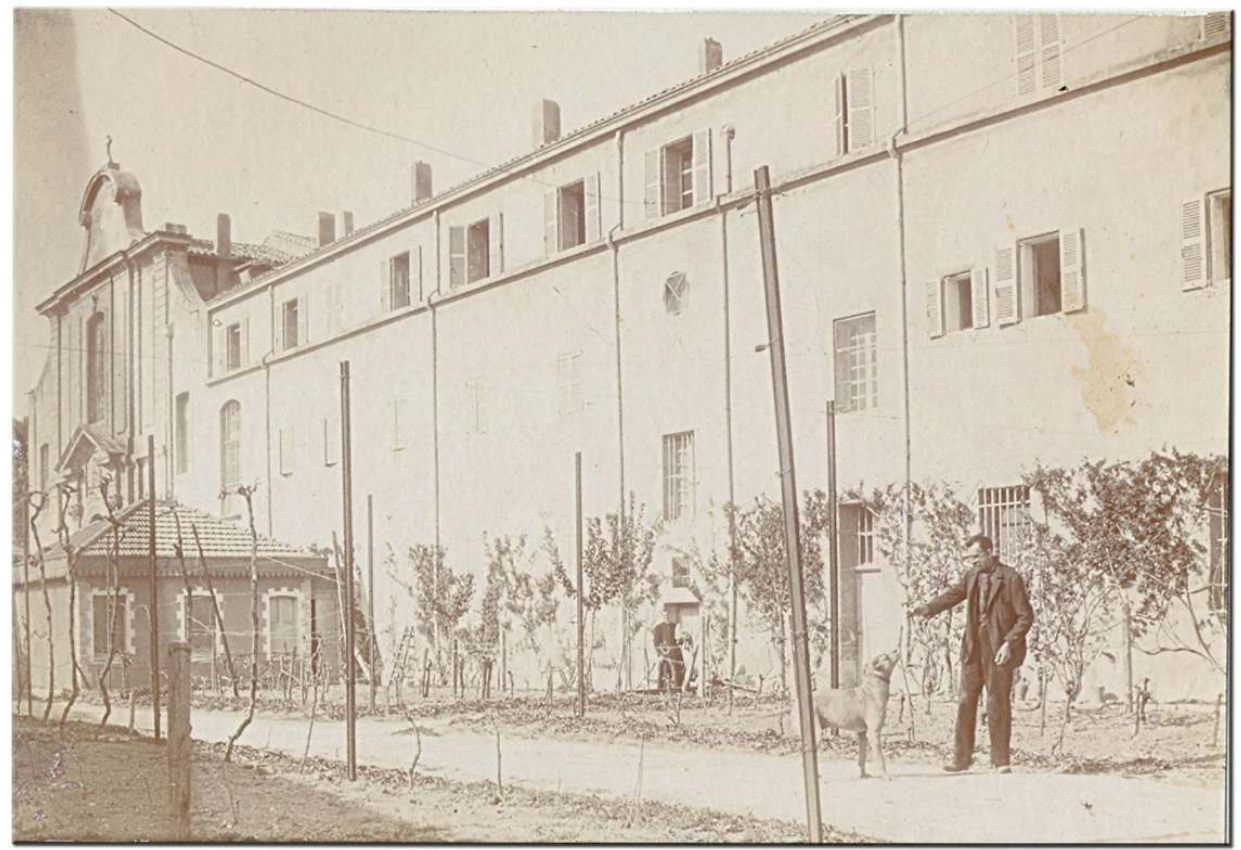

5 FI 5- Aile sud du bâtiment

Archives départementales de l'Hérault, dépôt-refuge des Archives départementales des Vosges et du ministère de la Guerre. Les fonds accueillis au printemps 1918 furent protégés dans l'ancien couvent des Récollets, puis grand séminaire de Montpellier, siège, depuis 1910, des Archives départementales de l'Hérault. Les archives locales, celles évacuées des Vosges, puis du ministère de la Guerre cohabitèrent dans les cellules des deux étages, les couloirs, le cloître et la chapelle du bâtiment, sur 4 ou 5 m de hauteur. Léon Gautier (1875-1926), employé du ministère de la Guerre, garda ce dépôt jusqu'au printemps 1919. Ces pièces, ici vers 1950, témoignaient encore de l'atmosphère et des installations de 1918-1919.

(c) Arch. dép. Hérault, 5 Fi 5. (c) J. Duvaux, 2011. Aile sud du couvent des Récollets à Montpellier, vers 1900. 
Figure 10

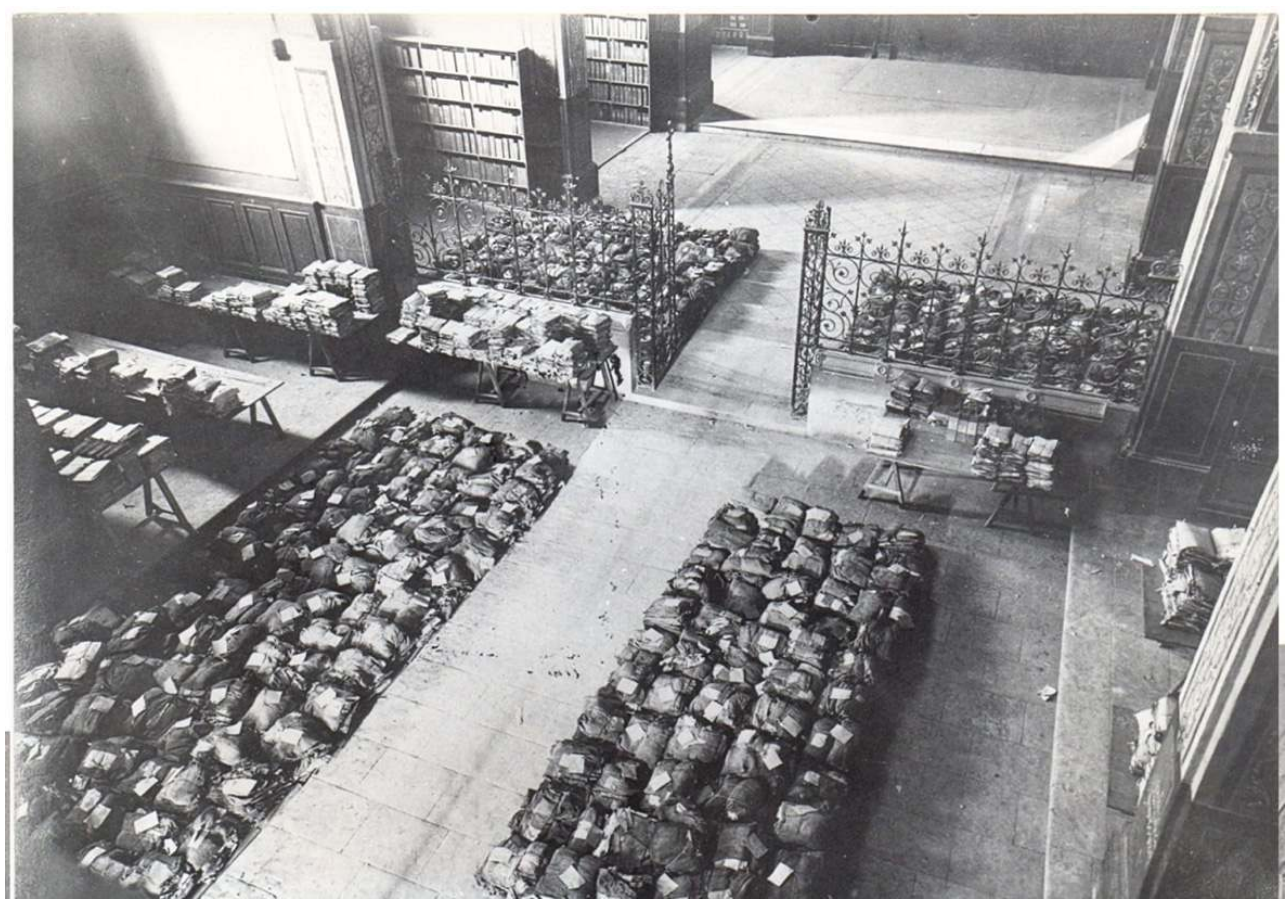

Vue de la nef de l'église conventuelle convertie en dépôt des Archives départementales de l'Hérault vers 1950.

(c) Arch. dép. Hérault, 5 Fi 95. (c) J. Duvaux, 2011.

Figure 11

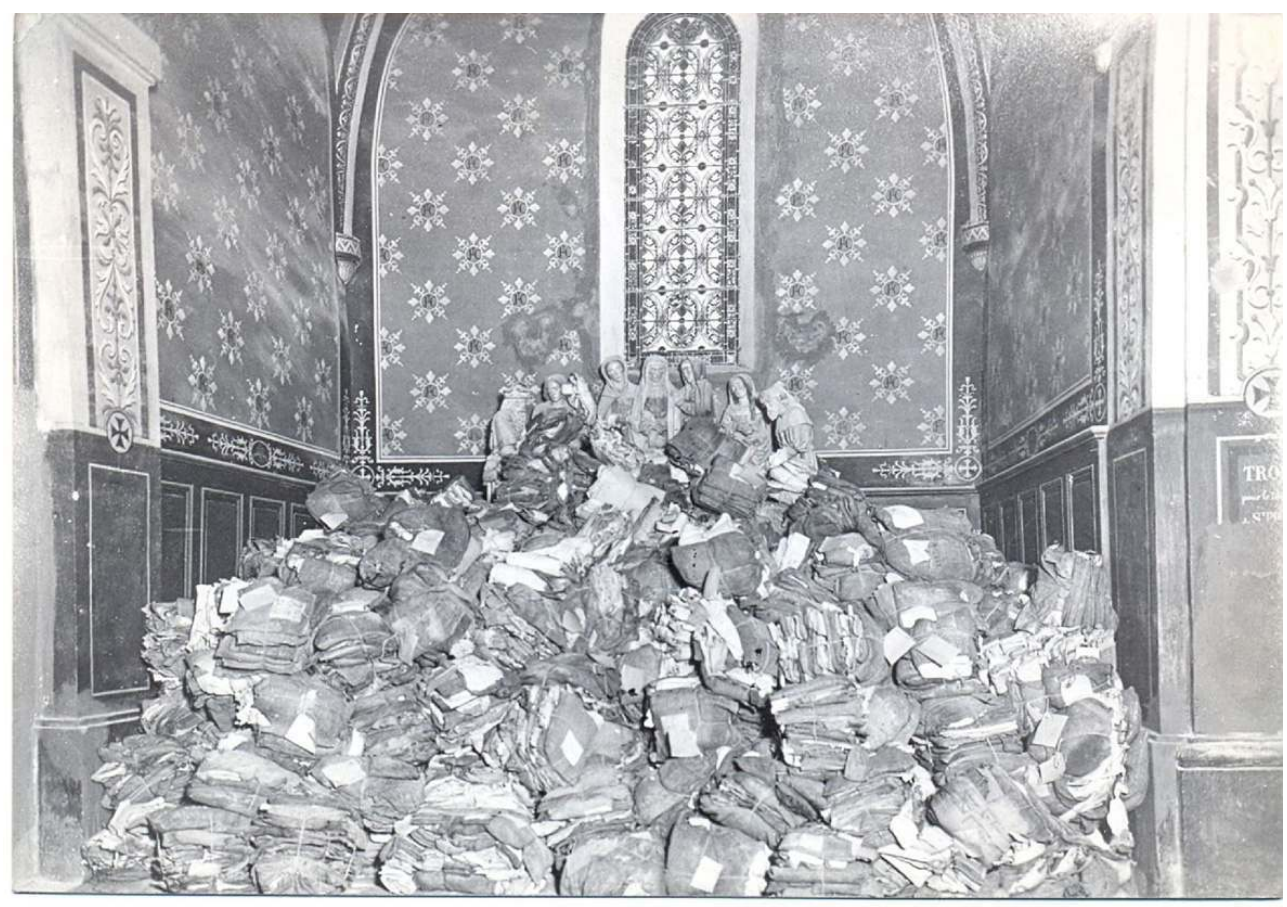

Vue de l'abside d'une chapelle latérale dans l'église conventuelle, affectée au stockage d'archives, vers 1950.

(c) Arch. dép. Hérault, 5 Fi 95. ㄷ J. Duvaux, 2011 


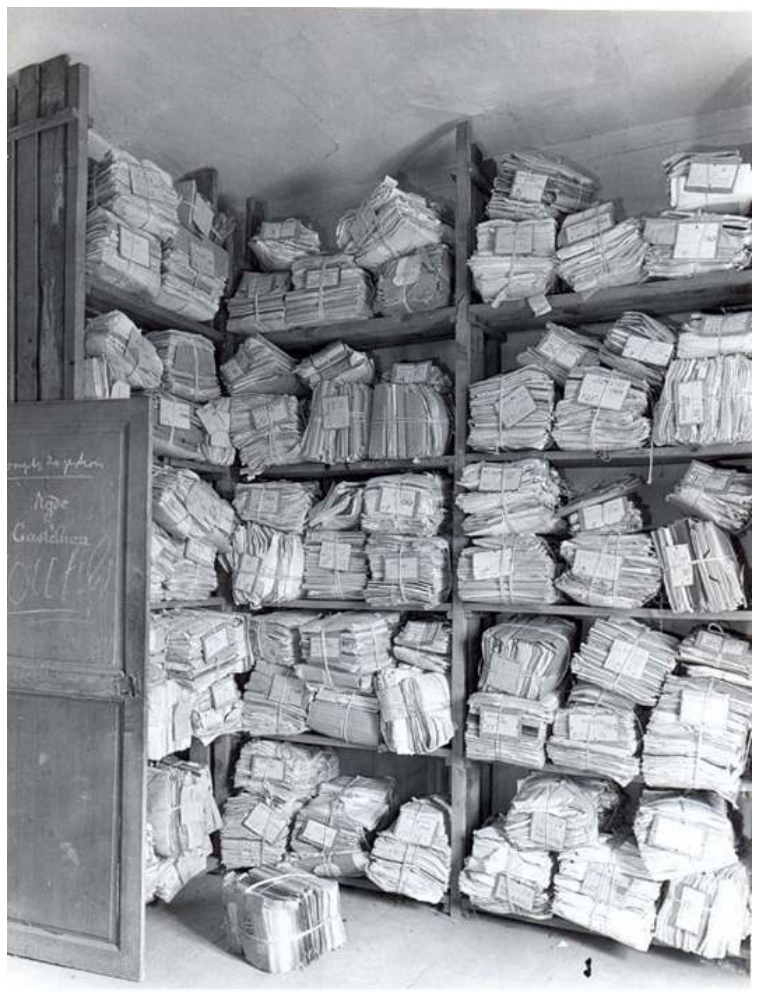

Vue d'une cellule de l'ex-couvent des Récollets, servant de magasin d'archives, vers 1950.

(c) Arch. dép. Hérault, 5 Fi 41. (c) J. Duvaux, 2011.

Ce mouvement d'évacuation à grande échelle n'est pas propre au réseau territorial du nord-est de la France. Aux Archives nationales, s'opposant à l'avis de Louis Lafferre, ministre de l'Instruction publique et des Beaux-Arts, qui l'invite à maintenir les fonds précieux dans les caves de l'hôtel de Soubise, Langlois préfère décider l'évacuation, après avoir appris le 14 avril que les ministères de la Guerre et des Affaires étrangères faisaient transporter leurs archives à l'arrière. Du fait des menaces de bombardements à longue portée et par avions nocturnes, une commission d'évacuation travaille, à partir du $1^{\mathrm{er}}$ juin 1918, sous la présidence du ministre de l'Instruction publique, et en présence de Langlois, à répartir les fonds inestimables en trois parts : $1^{\circ}$ ) « les monuments les plus illustres et [...] les plus précieux (musée, registres du Trésor des chartes, aveux et dénombrements de l'ancienne Chambre des comptes, etc.), [...] de quoi remplir plusieurs wagons »; $2^{\circ}$ ) « les collections du même genre, mais composées en partie de monuments trop fragiles pour subir sans dommages des transferts un peu rudes (layettes du Trésor des chartes, à cause des sceaux) »; $3^{\circ}$ ) « tout le reste $»^{53}$. Les Archives départementales de la Gironde, à Bordeaux, étant retenues, un premier convoi de trois wagons de chemins de fer, contenant 60 tonnes de documents sur parchemin et sur papier (contenu de l'Armoire de Fer, collections du musée, diplômes carolingiens, aveux des chambres des comptes notamment), quitte Paris, le 16 juin 1918. Les suivants comprennent les fonds des États d'Artois, les archives municipales d'Arras et de Reims, envoyées à Toulouse, en particulier pour ménager la place nécessaire, dans ces mêmes caves, aux collections réputées trop fragiles (seconde catégorie) par la commission d'évacuation. Les étalons du mètre et du kilogramme sont rendus provisoirement au Service des poids et mesures ${ }^{54}$. 

patrimoniales à Paris s'efforcent de préserver leurs archives à la même période. «En vue de parer au danger d'incendie ou pour le sauvetage des documents ", l'archiviste de la Seine choisit ainsi un refuge au sous-sol, dans le local du calorifère de l'aile gauche - « la sécurité y a même été augmentée par la superposition de liasses sur le plancher du dépôt »; durant six mois, du $1^{\mathrm{er}}$ avril au $1^{\mathrm{er}}$ octobre 1918, la salle de lecture et les bureaux, fermés et munis d'un avis affiché - « Toute personne qui restera dans la salle de travail ou dans les bureaux en cas de bombardement le fera sous son entière responsabilité »-, sont déplacés; la sélection des documents à évacuer est révisée et augmentée et 7251 cartons de registres d'état civil et des tables décennales de Paris et des communes de la Seine sont préparés à l'évacuation, grâce à un crédit préfectoral supplémentaire ; des circulaires aux maires de Paris et de la banlieue parisienne sont préparées pour les inviter à prendre de telles mesures. Au milieu du mois d'août, devant l'évolution militaire, tout est suspendu ${ }^{56}$.

\section{Le bilan et les actions de l'immédiat après-guerre : réparations, restitutions, reconstitutions}

Au mois de mai 1918, les prémices de la fin du conflit se font sentir. Le directeur des Archives de France reconnaît que «la situation est redevenue normale, par suite de démobilisation, dans six départements où le service des archives était suspendu ou compromis par l'absence de son chef : Allier, Cantal, Côte-d'Or, Seine-et-Oise, Deux-Sèvres et Yonne ", remarque qui ne s'applique pas à l'Aube, dont le service, jusque-là ouvert, ferme précisément à cette période. Par ailleurs, les archivistes non mobilisés sont, pour la plupart, aussi employés "en dehors de leurs fonctions ordinaires, aux services des réfugiés, du ravitaillement, de la censure. Quelques-uns prêtent même leur concours pour la gestion des camps de concentration de prisonniers civils $»^{57}$. Le ministre de l'Instruction publique ayant décidé, après l'armistice, le 11 novembre 1918, que les postes vacants dans les services d'archives départementales ne seraient pourvus qu'après la démobilisation générale des réserves, ce n'est donc que dans son rapport annuel du $1^{\mathrm{er}}$ mai 1920 que Langlois peut constater que vingt places nouvelles d'archivistes départementaux ont été pourvues ${ }^{58}$; la Meuse et la Haute-Saône seules restent dépourvues de directeur, leurs titulaires (Paul d'Arbois de Jubainville et Auguste Eckel) ayant rejoint les postes recréés de la Moselle et du Bas-Rhin.

\section{Reprendre pied sur le territoire et dresser le bilan des pertes}

Si Langlois peut, dès après l'armistice, en mai 1919, au retour de Bordeaux, dresser un bilan très positif des caisses des Archives nationales et même se réjouir que l'hôtel de Guise, encadré, pendant des semaines, par les obus, n'ait jamais été touché, ou que le musée des Archives, réorganisé, soit incessamment rouvert au public, pour profiter de la présence à Paris des " étrangers qu'attire à Paris la Conférence de la paix »"59, la situation est loin d'être analogue dans le réseau territorial. Dès le 13 octobre 1918, les deux ministres de l'Instruction publique et du Blocus adressent aux préfets des départements en bordure du front des instructions conjointes pour pourvoir au sauvetage immédiat des archives des régions en cours de libération, leur demandant ensuite de préciser les moyens de transport nécessaires ${ }^{60}$. 


\section{Le cas des trois départements occupés (Aisne, Ardennes, Nord)}

«Trois départements avaient été, au commencement de la guerre, recouverts si vite par l'invasion que leurs chefs-lieux, avec tout ce qui s'y trouvait, étaient tombés au pouvoir de l'ennemi : Aisne, Ardennes, Nord. L'invasion est restée là, étale, pendant quatre ans. Dans quel état y retrouverait-on, après le reflux, les archives départementales et autres?" ", s'interroge Langlois. Dès la fin octobre 1918, il se rend à Lille, sur ordre du ministre de l'Instruction publique, pour constater que le dépôt des Archives départementales du Nord, «admirablement défendu par M. l'archiviste Bruchet pendant quatre ans contre les offres et les menaces d'évacuation faites par les Allemands », était intact; il se rend ensuite, avec Bruchet, aux Archives municipales de Douai et de Lille, suivi par Chassaing de Borredon, archiviste aux Archives nationales; enfin à Cambrai, lors même de la bataille de début novembre 1918, prenant conscience que l'incendie de l'hôtel de ville avait été alimenté par les archives de la ville, extraites des caves où elles avaient d'abord été mises à l'abri' ${ }^{61}$.

Dans l'Aisne, Broche, archiviste départemental, mobilisable, avait dû quitter son poste lors de l'invasion de 1914. Les archives anciennes de son service, déménagées par les Allemands, ont été retrouvées à peu près intactes dans d'autres édifices de Laon, à l'exception de la disparition du fonds de la seigneurie de Roucy, mais les archives modernes ont été en partie détruites ou dispersées. Dans l'Aisne récupéré, Broche mène la même tournée d'inspection que Langlois dans le Nord. Durant l'hiver 1919-1920, à la demande du préfet de l'Aisne, Chassaing de Borredon se rend à Saint-Quentin pour remettre en ordre les vestiges des archives et de la bibliothèque municipales, abandonnées depuis l'armistice ${ }^{62}$.

Dans les Ardennes, Laurent, archiviste départemental, avait dû quitter son poste en 1914 sur ordre du préfet et était parti s'occuper du chartrier de Rethel, partie des archives de la principauté de Monaco. Les mesures de conservation urgentes prises aux Archives départementales des Ardennes après l'évacuation, l'ont été par Courteault, conservateur adjoint.

\section{Le cas des communes de la zone du front et de la zone envahie}

41 Sans qu'elle soit encore précisément évaluée, l'importance de la destruction des archives des communes rurales s'impose avec l'armistice. Dès le 26 novembre 1918, le ministre de l'Instruction publique invite les archivistes départementaux à dresser sur fiches la nomenclature des pertes subies dans leur ressort pour les archives de toute espèce, les premières fiches retournées à la direction des Archives devant servir à établir une méthode de description uniforme ${ }^{63}$. En décembre 1918, les archivistes des départements de la zone du front se lancent dans cette tâche et adressent à la direction des Archives les réponses de leurs communes sous forme de petites fiches, encore intégralement conservées $^{64}$. La tâche est considérable. Le témoignage transmis par E. Duvernoy, archiviste départemental de la Meurthe-et-Moselle, au directeur des Archives nationales le 11 décembre 1918 illustre particulièrement bien les conditions de ce recensement (communes désertées, absence de moyens de transport, froid de l'hiver) :

La vérification de beaucoup de dépôts d'archives est fort difficile en ce moment, parce que, dans nombre de communes occupées jusqu'à une date récente par l'ennemi, il n'y a plus ni population civile, ni administration municipale. On n'y voit que des soldats français et surtout américains, dont il n'y a à attendre aucun 
renseignement. Comme les maisons de ces villages sont ou détruites, ou dans le plus mauvais état, et qu'ils manquent du reste de toute ressource, l'autorité ne laissera pas la population y rentrer avant le printemps sans doute.

J'ai fait le compte des communes de Meurthe-et-Moselle qu'il me faudra visiter parce qu'elles ont été ou occupées ou bombardées par l'ennemi et que, dans les deux cas, leurs archives ont pu avoir à souffrir. En voici le nombre par arrondissements : arrondissement de Briey; 126 communes; de Lunéville : 150 ; de Nancy : 67 ; de Toul : 50 ; total : 393. Je dois dès maintenant indiquer qu'il me faudra un large délai pour visiter ce grand nombre de communes, dont la plupart sont fort éloignées de Nancy, puisqu'elles dépendent des arrondissements excentriques de Briey et de Lunéville. Les moyens de transport font presque complètement défaut. J'avais espéré pouvoir me servir d'une automobile militaire, mais il n'y en a pas de disponible. Quant aux trains, ils ne sont pas rétablis sur les lignes secondaires et ne le seront pas avant plusieurs mois. Sur les lignes principales, ils sont en très petit nombre et ont des retards énormes, en sorte qu'on passe beaucoup de temps à faire peu de besogne. Et la brièveté des jours dans cette saison est encore une entrave.

Je compte néanmoins procéder à cette vérification avec toute l'activité que me permettront ces conditions difficiles et aussi la nécessité de ne pas négliger totalement le dépôt départemental, où il y a beaucoup à faire pour remettre en place et en bon ordre les volumineuses collections déplacées par crainte des bombardements ${ }^{65}$.

Ces difficultés logistiques réelles sont prises en compte par la direction des Archives dans la circulaire du 13 décembre 1918 aux préfets de l'Aisne, des Ardennes, de la Meuse, de Meurthe-et-Moselle, du Nord, de l'Oise, du Pas-de-Calais, de la Somme et des Vosges, mettant en avant «la grande importance des archives pour la sauvegarde des intérêts publics et privés » pour requérir la mise à disposition des archivistes d'une voiture militaire de récupération ${ }^{66}$. Les conditions de recensement ainsi améliorées, des milliers de fiches furent renvoyées par les dix archivistes concernés, la plupart au cours de l'hiver 1919-1920. Le délai d'exécution s'est trouvé parfois allongé, jusqu'en janvier 1920 par exemple dans le cas de l'Aisne, où il fallait attendre que les Allemands aient restitué les caisses d'archives qu'ils avaient envoyées à l'arrière. Lorsqu'à l'automne 1919, la direction des Archives s'étonne de n'avoir encore reçu le résultat de l'inspection des communes de Meurthe-et-Moselle, l'archiviste départemental laisse à nouveau un témoignage précieux des conditions de ce recensement historique :

Je tiens à dire que mes voyages dans près de 400 communes du département n'ont pas été faciles, afin de me disculper de tout reproche de négligence ou de lenteur. Pendant tout l'hiver, il m'a été impossible d'obtenir des automobiles, le service des Régions libérées n'étant pas encore organisé. J'ai dû circuler à pied et en chemin de fer à un moment où le service des trains était détestable. J'ai disposé pour la première fois d'une auto le 7 mai [1919] et la seconde, le 24 mai seulement. Pendant les mois de juin et de juillet, j'ai obtenu assez régulièrement des autos et visité un grand nombre de communes, mais il m'a fallu me rendre à pied dans quelques-unes, les chemins qui y conduisent étant impraticables aux voitures et les ponts détruits. En août, il est devenu à peu près impossible d'avoir des autos, presque tous les véhicules étant en réparation, par suite d'un usage intensif et en outre l'essence manquant. J'ai dû, par une forte chaleur, achever à pied l'arrondissement de Lunéville et commencer à pied celui de Briey. Le 10 septembre seulement, j'ai pu de nouveau obtenir des autos pour achever mes vérifications. Mon dernier voyage a été achevé le 4 octobre.

Il est à peine besoin de dire que, dans ces courses, j'ai eu, par suite du mauvais état du matériel, de nombreuses pannes et quelques accidents, dont aucun n'a été grave, mais qui tous m'ont fait perdre du temps. D'autre part, les maires et les secrétaires de mairie étant souvent absents, surtout en août et en septembre, il m'a fallu 
retourner deux, trois et même quatre fois dans certaines communes pour arriver à me faire ouvrir les archives ${ }^{67}$

Bilan des pertes des archives communales des départements envahis ou occupés, hiver 1919-1920

[d'après les fiches-réponses aux instructions ministérielles des 26 novembre 1918 et 6 mai 1919]

\begin{tabular}{|c|c|c|c|c|c|}
\hline \multirow[b]{2}{*}{ DÉPARTEMENT } & \multirow[b]{2}{*}{$\begin{array}{l}\text { Nombre de } \\
\text { communes } \\
\text { touchées }\end{array}$} & \multicolumn{3}{|l|}{ Dont : } & \multirow[b]{2}{*}{$\begin{array}{l}\text { Retour du } \\
\text { recensement } \\
\text { aux Archives } \\
\text { nationales }\end{array}$} \\
\hline & & $\begin{array}{l}\text { archives } \\
\text { totalement } \\
\text { détruites }\end{array}$ & $\begin{array}{l}\text { archives } \\
\text { détruites } \\
\text { en partie }\end{array}$ & $\begin{array}{l}\text { archives } \\
\text { disparues } \\
\text { ou } \\
\text { enlevées }\end{array}$ & \\
\hline AISNE & 598 & 66 & 441 & 91 & $\begin{array}{l}23 \text { et } 24,28 \text { et } 30 \\
\text { octobre } 1919 ; 2,8 \text {, } \\
16 \text { et } 26 \text { novembre } \\
1919 ; 15 \text { et } 22 \\
\text { décembre } 1919 \text {; } \\
30 \text { janvier } 1920\end{array}$ \\
\hline NORD & 422 & 36 & 386 & & $\begin{array}{lrrr}25 & \text { juin } & \text { et } & 12 \\
\text { novembre } & 1919 & \end{array}$ \\
\hline ARDENNES & 383 & 85 & 286 & 12 & 4 août 1919 \\
\hline SOMME & 335 & 68 & & 81 & $\begin{array}{lcc}22 & \text { juillet } & \text { et } \\
\text { décembre } 1919 & \end{array}$ \\
\hline $\begin{array}{l}\text { MEURTHE-ET- } \\
\text { MOSELLE }\end{array}$ & 245 & 51 & 194 & & $\begin{array}{l}11 \text { décembre } 1918 ; \\
17 \text { octobre et } 4 \\
\text { novembre } 1919\end{array}$ \\
\hline MEUSE & 225 & 139 & 86 & & 3 juillet 1919 \\
\hline MARNE & 153 & 70 & 83 & & $\begin{array}{l}4 \text { et } 25 \text { novembre } \\
1919 ; 10 \text { décembre } \\
1919\end{array}$ \\
\hline PAS-DE-CALAIS & 130 & 66 & 64 & 8 & [1919] \\
\hline OISE & 111 & 41 & 70 & & 16 octobre 1919 \\
\hline VOSGES & 46 & 9 & 37 & & 19 février 1919 \\
\hline
\end{tabular}

Ce recensement, mené essentiellement en 1919, portait sur les archives communales. Mais certaines initiatives, telle que celle du directeur des Archives départementales du Nord, qui élargit l'enquête à d'autres fonds d'archives de son ressort (422 dépôts d'archives communales, dix-sept dépôts d'archives hospitalières, trois dépôts de souspréfectures, un dépôt de greffe, tous en zone occupée, c'est-à-dire dans les arrondissements d'Avesnes, Cambrai, Douai, Lille, Valenciennes et dans quinze communes de l'arrondissement d'Hazebrouck), laissent un témoignage sans appel du niveau destructif de la Grande Guerre sur le patrimoine archivistique du croissant occupé au nord-est de la France. 
En ce qui concerne les archives communales, sur 565 localités occupées, 143 ont gardé des archives intactes, 36 ont eu leur dépôt complètement anéanti, 386 ont subi des pertes plus ou moins considérables. Les archives hospitalières ont été aussi gravement éprouvées : 14 dépôts ont été détruits, 29 ont pu être sauvegardés. Les archives départementales et celles de la préfecture sont intactes. Celles des souspréfectures de Cambrai et Valenciennes sont anéanties. La sous-préfecture d'Avesnes a subi des pertes importantes. Le greffe du tribunal de Cambrai est complètement incendié ${ }^{68}$.

Quant aux services d'archives départementales, Langlois conclut dans son rapport d'avril 1920 que « le département du Pas-de-Calais est, de tous les départements envahis, celui où les archives ont le plus souffert, le seul où le dépôt départemental ait été gravement éprouvé; les travaux indispensables de réinstallation et de reconstitution y seront plus laborieux et plus pénibles que partout ailleurs $»^{69}$.

\section{Le cas des départements annexés redevenus français (Moselle, Bas-Rhin et Haut- Rhin)}

La préoccupation du directeur des Archives pour ces trois départements n'est pas neuve ${ }^{70}$ ; aussi envoie-t-il à Metz, Strasbourg et Colmar, dès novembre 1918, Charles Schmidt, archiviste aux Archives nationales, pour faire une première reconnaissance des archives et vérifier l'application de mesures conservatoires. En janvier 1919, Langlois s'y rend à son tour - les postes d'archivistes en chef sont encore vacants - « pour se rendre compte de la nature des très nombreux échanges effectués entre les dépôts d'Alsace-Lorraine et ceux de l'Allemagne propre, sous le régime établi par le traité de Francfort, et des questions qui se poseront lors du versement des papiers de l'administration allemande du Reichsland, depuis, 1871, au dépôt de Strasbourg ${ }^{71}$. Cette mission lui permet de concevoir un projet de réorganisation administrative des trois dépôts :

$\left.1^{\circ}\right)$ Si l'on maintient les subdivisions administratives actuelles (Haute et BasseAlsace, Lorraine), calquées d'ailleurs sur les départements français, il faudra maintenir trois archivistes, l'un à Strasbourg, l'autre à Colmar, le troisième à Metz. $2^{\circ}$ ) Il y a aura lieu cependant de donner aux archivistes de Strasbourg, pour l'Alsace, et de Nancy, pour la Lorraine, une autorité de direction sur les archivistes de Colmar et de Metz. On constituera ainsi des archives d'Alsace et des archives de Lorraine. Les deux archivistes provinciaux seront d'ailleurs placés près des deux universités de Strasbourg et de Nancy.

$3^{\circ}$ ) La tâche commune des archivistes de Strasbourg, Colmar, Metz, sera de faire entrer dans leur dépôt les papiers de l'administration allemande depuis 1870 (registratures des Bezirks [sic]).

$4^{\circ}$ ) La tâche spéciale de l'archiviste de Strasbourg sera de crééer un dépôt d'archives d'Alsace-Lorraine (Landsarchiv), prévu dès 1848 par l'archiviste Wiegand, où l'on réunira les archives des différents ministères de Strasbourg et d'un certain nombre d'administrations supprimées. Il aura sans doute aussi, ultérieurement, à créer un dépôt d'archives économiques (Wirtschaftsarchiv), analogue à celui de Cologne ou à celui de Bâle ${ }^{72}$.

D'août à novembre 1919, il revient ensuite à Ch. Schmidt, en qualité de «directeur des archives d'Alsace et de Lorraine» près du Commissariat général de la République à Strasbourg, de réorganiser le service des archives en Alsace et en Lorraine jadis annexée, laissant de sa mission un rapport daté du 26 janvier $1920^{73}$. 


\section{Chercher à obtenir réparation}

Pour les dépôts d'archives des régions Nord et Est, pillés, endommagés et détruits de 1914 à 1918, le traité de Versailles, signé le 28 juin 1919, a prévu deux types de dédommagements : les réparations et les restitutions. Pour les documents détruits, le traité de paix donne à la France le droit d'en réclamer la valeur estimative, en argent strictement, devant la Commission internationale des réparations ${ }^{74}$. Par son instruction du 26 novembre 1918, déjà citée, la direction des Archives nationales presse les archivistes départementaux de fournir les fiches de recensement demandées; ils sont également avertis, le 6 mai 1919, que, selon la circulaire du ministre de la Reconstitution industrielle du 19 avril 1919, l'Allemagne sera tenue de fournir aux gouvernements alliés intéressés les éléments de réparation des régions dévastées, en englobant les archives détruites, à lister à la Commission interalliée pour le 31 décembre 1919, dans les « objets de valeur de nature artistique, historique ou littéraire, non susceptibles de reproduction et qui ont été saisis ou détruits par l'ennemi, ou détruits en conséquence directe des opérations militaires, et que [les] gouvernements désirent voir remplacés par des objets analogues existant en Allemagne $»^{75}$.

Une conférence interministérielle, le 2 décembre 1919, décide que le ministère de l'Instruction publique serait chargé de présenter l'estimation des dommages subis par les dépôts d'archives appartenant à l'État, tandis que, par application de la loi du 17 avril 1919, celui des Régions libérées devait présenter l'estimation des dommages subis par les dépôts d'archives appartenant à des personnes morales autres que l'État (départements, communes). L'évaluation des pertes est une question cruciale, nécessitant d'accorder le ministère de l'Instruction publique et celui des Régions libérées autour de principes communs d'estimations réciproques. C'est par un accord de décembre 1919 que la détermination de la méthode générale, des barêmes et des tarifs raisonnables incombe au ministère de l'Instruction publique, jugé plus compétent pour l'estimation des archives perdues, quel que soit le statut du dépôt d'archives concerné.

Une conférence des «archivistes des régions libérées» fut donc organisée, le 25 janvier 1920, aux Archives nationales, sous la présidence du directeur des Archives, sur la base d'un avant-projet dressé par Bruchet, archiviste départemental du Nord ${ }^{76}$. Adoptées à l'unanimité, les dispositions furent incorporées dans la circulaire aux préfets du 14 février 1920, conjointe aux ministres de l'Instruction publique et des Régions libérées, qui prévoyait, pour les archives départementales, les sous-préfectures, les communes, les hospices et les greffes (état civil), des tarifs d'indemnisation, d'une part, pour les documents irremplaçables, à évaluer par catégorie par comparaison avec les archives municipales de Cambrai et d'Estaires (Nord), dont les inventaires étaient imprimés, d'autre part, pour les documents reconstituables (état civil, registres de délibérations, bibliothèques administratives.... $)^{77}$. Le ministère des Finances, lui, se réservait l'évaluation des documents cadastraux. Le dossier complet des évaluations dressées en conséquence fut transmis en mars 1920 au secrétariat français de la Commission des réparations ${ }^{78}$. 


\section{Revendiquer la restitution des fonds d'archives prélevés par l'Allemagne}

51 Dans le panorama des négociations de la sortie de guerre, Langlois s'est efforcé de faire reconnaître très vite la place du patrimoine écrit. En novembre 1918 et mars 1919, pour remise à la Conférence de la paix, la direction des Archives a élaboré des notes relatives aux stipulations à insérer dans le traité en ce qui concerne les archives ${ }^{79}$.

Le premier fonds concerné est celui des archives de la principauté de Salm, qui, avec plusieurs documents publics, avait été prélevé des Archives départementales des Vosges, en application d'une convention additionnelle au traité de Francfort, signée à Berlin et Paris les 21 et 31 juillet 1871, qui avait annexé à la Basse-Alsace onze communes vosgiennes du canton de Schirmeck et sept autres de celui de Saâles, ressort historique de la principauté de Salm. Profitant de l'absence de directeur, poste non pourvu de novembre 1871 à juin 1873, les Allemands emportèrent d'Épinal 70 liasses des séries anciennes ( $\mathrm{C}$ et $\mathrm{E}$ ) et modernes ( $\mathrm{M}, \mathrm{N}, \mathrm{O}, \mathrm{P}, \mathrm{S}$ et $\mathrm{T})$, dont les titres de la principauté de Salm ${ }^{80}$. En 1919, André Philippe, archiviste départemental, saisit Ch.-V. Langlois, énumérant les onze liasses du fonds de la principauté de Salm (1357-1789), enlevées en 1871 ${ }^{81}$.

L'autre enjeu des démarches de revendication engagées au sortir de la guerre concerne les fonds des archives de Montbéliard, qui avaient été répartis, entre l'an III et 1840, entre les départements du Doubs, de la Haute-Saône et du Haut-Rhin, mais aussi entre le département du Bas-Rhin et les Archives nationales. Après 1870, plusieurs liasses du fonds de Montbéliard de Colmar furent transportées à la filiale des archives wurtembergeoises à Ludwigsburg, près de Stuttgart, tandis qu'en juillet 1883, une autre transaction entre l'Allemagne et le Wurtemberg rendait à ce dernier ce qui en était sorti en 1809, notamment les archives conservées à Strasbourg, en échange d'un fonds de l'Ordre teutonique. La demande de Langlois au ministre de l'Instruction publique, concernant ce fonds de Montbéliard réparti entre les services d'archives du Bas-Rhin et du Haut-Rhin, est la suivante :

Il devra être stipulé, semble-t-il, que ces fonds, qui ont un caractère local, devront être restitués par le Würtemberg. Il faut considérer toutefois qu'il est intervenu, pendant le régime allemand, un assez grand nombre de conventions d'échange entre les dépôts d'Alsace-Lorraine et ceux d'Allemagne. Tous ces " échanges » ne paraissent pas avoir été spécialement désavantageux pour les dépôts alsaciens et lorrains ${ }^{82}$.

Concernant le calendrier des restitutions, aux termes du l'article $245 \mathrm{du}$ traité de Versailles, "dans les six mois qui suivront la mise en vigueur du présent traité, le Gouvernement allemand devra restituer au Gouvernement français les [...] archives [...] enlevées de France par les autorités allemandes au cours de la guerre de 1870-71 et de la dernière guerre, suivant la liste qui lui en sera adressée par le Gouvernement français ». Cette liste, établie par Ch.-V. Langlois le 31 octobre 1919 et fournie au secrétariat français près de la Commission internationale des réparations le 4 novembre, comportait quatre fonds : les archives de la principauté de Salm des Archives départementales des Vosges, enlevées en 1871 ; le fonds de Montbéliard des Archives départementales du Haut-Rhin, enlevé après 1870 ; le fonds de Montbéliard des Archives départementales du Bas-Rhin, après juillet 1883 ; le chartrier de Roucy des Archives départementales de l'Aisne, enlevé au cours de la guerre 1914-1918 ${ }^{83}$. 
$55 \mathrm{Au}$ vrai, les restitutions documentaires se préparaient côté allemand depuis le printemps 1919: dès avril, étaient rassemblés nombre de documents enlevés, en 1918 surtout, dans les pays français qu'ils évacuaient. Aussi, la Commission allemande d'armistice avait-elle pu installer, début 1919, une « sous-commission pour la restitution des documents ", qui, le 21 mars, prévient le général Nudant, président de la Commission interalliée d'armistice, que trois liasses de cartes du cadastre avaient été expédiées de Berlin à Mayence, siège de l'état-major de la $\mathrm{X}^{\mathrm{e}}$ Armée, pour restitution au commissaire de la République à Metz $^{84}$. Elles y sont réceptionnées en avril; parmi elles, plusieurs documents cadastraux et plans divers, sans intérêt pour la Lorraine occupée, sont envoyés le 22 avril au Secrétariat général de l'Armée, à Paris, rue de Grenelle ${ }^{85}$. Par ailleurs, début avril 1919, un inspecteur délégué à la récupération des documents prévenait le commissaire de la République à Metz que la commission allemande d'armistice et la commission interalliée permanente d'armistice s'étaient accordées pour lui faire expédier un ensemble assez considérable, dont une reconnaissance contradictoire fut menée à leur arrivée à Metz, par un délégué allemand, selon le protocole d'exécution de l'armistice :

$\left.1^{\circ}\right)$ des plans cadastraux de nombreuses communes des départements de l'Aisne, des Ardennes, de la Meuse, de Meurthe-et-Moselle et des Vosges, qui avaient été transportés à Berlin $[. ..] ; 2^{\circ}$ ) des manuscrits, incunables et autres imprimés provenant de la bibliothèque de Saint-Mihiel, qui avaient été transportés à Leipzig $\left.[. ..] ; 3^{\circ}\right)$ vingt-deux registres d'état civil du tribunal de Laon, qui avaient été transportés à Carlsruhe; $4^{\circ}$ ) les manuscrits de la bibliothèque du château de Hombourg-Kedange (arr. Thionville), qui auraient été emportés par le Dr Wolfram, ancien directeur de la bibliothèque de l'université de Strasbourg $[. ..] ; 5^{\circ}$ ) les documents des archives départementales de Lorraine, qui avaient été transportés à Leipzig; $6^{\circ}$ ) les documents des archives de la ville de Metz, qui avaient été transportés à Leipzig86.

56 Au début de l'été 1919, le trésorier payeur central de Paris, M. de Celles, fut placé, en qualité de séquestre général, à la tête d'une commission des biens restitués. Selon la demande faite par le ministre de l'Instruction publique au ministre des Régions libérées le 24 juin 1919, il se tint en relation constante avec la direction des Archives ${ }^{87}$, autorisant Langlois, dans son rapport du $1^{\text {er }}$ mai 1920, à affirmer avec confiance que les démarches suivaient leur cours ${ }^{88}$. En 1920, M. Christiany, archiviste aux Archives de la Moselle, reçut mission de conduire les démarches des récupérations et obtint en effet de l'autorité allemande la restitution de plusieurs fonds, les plus considérables étant ceux dits de Montbéliard ; les archives du comté de Horbourg et de la seigneurie de Riquewihr furent rendues en 1921 aux Archives du Haut-Rhin ; la partie du fonds primitif de Montbéliard, déposée avant 1870 aux Archives du Bas-Rhin, fut recouvrée en 1920, mais remise, sur ordre du ministre de l'Instruction publique, aux Archives départementales du Doubs ; au printemps 1921, les autorités allemandes promettaient de restituer aux Archives de la Moselle le fonds de la Chambre impériale de Wetzlar ${ }^{89}$. En avril 1922, furent restituées aux Archives départementales des Vosges, par la préfecture du Bas-Rhin, 28 liasses prélevées en 1871, surtout relatives à la principauté de Salm; les documents administratifs postérieurs à 1790 concernant les dix-huit communes vosgiennes annexées à la BasseAlsace allemande demeurèrent, eux, aux Archives du Bas-Rhin ${ }^{90}$. 


\section{Repérer les archives françaises dans les zones occupées par les Alliés : l'opportunité de l'immédiat après-guerre} province de la Prusse rhénane (capitale: Coblence), Hesse Darmstadt (Darmstadt) principauté de Birkenfeld (Oldenbourg) et Bavière rhénane (Spire). En France, la direction des Archives s'intéresse très vite au sort des archives françaises produites deux cents ans plus tôt, sur ces mêmes territoires, et conservées en Allemagne depuis la période révolutionnaire et impériale, celles du département des Forêts (conservées à Luxembourg), de la Sarre (conservées à Coblence), de Rhin-et-Moselle (conservées à Coblence), de Mont-Tonnerre (conservées à Spire et Darmstadt) et de la Roër (conservées à Düsseldorf).

Avec l'accord du maréchal Foch, Ch. Schmidt, archiviste aux Archives nationales mis à disposition du service d'Alsace-Lorraine, après sa démobilisation, est envoyé en mission par Ch.-V. Langlois, du 18 au 31 janvier 1919, dans les territoires rhénans occupés par les armées françaises et alliées, avec le double objectif, « en prévision d'une occupation qui sera certainement longue, [de] rechercher les possibilités de travail qui s'offriraient aux savants et aux étudiants français désireux de visiter les dépôts de la rive gauche du Rhin » et «s'enquérir de l'état [des] documents relatifs à la période de la première occupation française de 1792 à $1814 »^{{ }^{11}}$. Après avoir visité les archives grand-ducales à Luxembourg, les archives municipales de Trêves, les archives provinciales de Coblence, les archives municipales de Mayence, les archives de Wiesbaden, de Spire et de Sarrebrück ${ }^{92}$, il en dresse un rapport le 4 février 1919.

L'administration militaire, elle aussi, relaie localement, en février-mars 1919, les préconisations du ministère de l'Instruction publique et des Beaux-Arts. Le 10 mars 1919, le maréchal Foch, commandant en chef des armées alliées, fait savoir au ministre de la Guerre qu'il venait de demander "aux commandants en chef des armées américaine, belge, britannique et française de prendre les mesures nécessaires pour assurer, dans les villes allemandes occupées par les alliés, la conservation des archives qui ont trait à la première occupation française (Révolution et Premier Empire) et pour en faciliter la communication aux savants qui désireraient y effectuer des recherches $"^{93}$, invitant encore, le 12 mars, les " personnes chargées des recherches historiques en zone anglaise » à se présenter au préalable au gouverneur anglais de Coblence, selon le souhait du maréchal Haig, commandant en chef les armées britanniques. À la tête de la VIII ${ }^{\mathrm{e}}$ Armée française, le général Gérard avertit le maréchal Foch des mesures prises dans son ressort, tout à fait significatives: surveillance des archives des villes de son territoire par les contrôleurs des cercles, mission donnée aux officiers ou hommes de troupe de les récoler et d'en dresser l'inventaire, réalisation d'une liste des archives de Spire par un officier d'état-major, "avec l'analyse sommaire de toutes les pièces concernant les différentes occupations françaises des pays rhénans ", jointe à des épreuves photographiques ${ }^{94}$.

Mais il apparait, début 1919 encore, que la direction des Archives n'est pas reconnue comme l'interlocuteur naturel, en matière de protection des archives issues de l'occupation révolutionnaire et impériale. C'est bien à la direction de l'Enseignement supérieur, sous tutelle du ministère de l'Instruction publique et des Beaux-Arts, que la section d'histoire moderne et contemporaine du Comité des travaux historiques s'adresse, en mars 1919, pour s'émouvoir des risques possibles de destruction ou de 
mutilation des archives d'État de Vienne et de la conservation des archives de la première occupation française dans les villes occupées par les Alliés. Alerté en ce sens, le ministre de l'Instruction publique transmet ces vœux au ministre des Affaires étrangères et au ministère de la Guerre ${ }^{95}$, sans en prévenir la direction des Archives. À l'initiative du général Mangin, commandant la $\mathrm{X}^{\mathrm{e}}$ Armée, l'administration militaire fait même dresser, début 1919, aux archives d'État de Coblence, une copie de la série des ordres généraux de l'armée de Sambre-et-Meuse et des ordres généraux de l'armée d'Allemagne durant la période révolutionnaire ( $1^{\text {er }}$ germinal an $\mathrm{V}-18$ nivôse an VI) et repérer la correspondance administrative et politique des généraux Hoche, Lefebre et Augereau avec l'administration civile des pays conquis sur la rive gauche du Rhin (commission intermédiaire, puis régie nationale, de ventôse an $\mathrm{V}$ à frimaire an $\mathrm{VI}$ ). Mangin adresse le résultat de ses repérages à la direction de l'Enseignement supérieur, qui finit, le 14 juin 1919, par les transmettre au directeur des Archives. La réponse immédiate de Langlois est l'occasion de rappeler l'hégémonie de principe que la direction des Archives doit exercer, à ses yeux, dans les relations avec les dépôts de la région rhénane, la réalisation d'inventaires détaillés et d'éventuelles copies sélectives de documents originaux intéressant l'histoire de France ${ }^{96}$. Dans le rapport de sa première tournée en Allemagne, rendu le 4 février 1919, Schmidt alertait déjà Langlois, du reste, des initiatives prises par l'autorité militaire et de la nécessité de "coordonner ces efforts et [d']organiser avec unité et méthode un travail de recherches, tant dans les archives allemandes qu'aux Archives nationales »:

J'ai appris et constaté que le commandement français se préoccupait de rappeler aux troupes le souvenir de la première occupation de 1792 à 1814. Chacune des armées publie un Bulletin, où, après les textes administratifs, on donne des études géographiques et historiques sur la région rhénane. Le général Mangin à Mayence, le général Gérard à Landau, sous la direction du général Fayolle, s'occupent activement de faire connaître aux officiers et aux soldats placés sous leurs ordres les ressources actuelles des pays rhénans et leur histoire pendant le cours du XIX ${ }^{\mathrm{e}}$ siècle. À Mayence [...], un jeune archiviste tire des archives locales la matière d'articles pour le Bulletin de l'armée ; à Spire, [...] les officiers chargés du contrôle civil s'intéressent particulièrement à l'histoire de la région ${ }^{97}$.

61 La reprise en main des opérations semble acquise au début de l'été 1919. La question des archives françaises des dépôts rhénans occupe l'ordre du jour de la séance de la Commission supérieure des Archives du 26 juin 1919. La direction des Archives, en accord avec le commissaire de la République, contrôleur général de l'administration civile des pays rhénans, veut faire déposer aux Archives nationales les documents analogues à ceux conservés aux Archives du Palatinat, à Spire, et intéressant l'histoire de l'ancienne occcupation française du pays ${ }^{98}$; la section moderne du Comité des travaux historiques a également souhaité que des copies soient faites des archives de la commission intermédiaire de Bonn, présidée par le général Hoche.

62 Aux frais de l'administration des Territoires rhénans, Ch. Schmidt est d'ailleurs missionné à nouveau, du 19 juillet au 8 août 1919, dans les villes de la rive gauche du Rhin, « afin de choisir, dans les archives publiques, les inventaires manuscrits des fonds de documents relatifs à la première administration française du pays, il y a un siècle, et pour en faire réaliser la copie dans l'interêt de nos grands dépôts publics et des historiens français ». Son rapport final, le 13 août 1919, rend compte de sa visite des archives municipales et des archives économiques de la région rhéno-westphalienne à Cologne, des archives de Coblence, de Mayence, de Spire et de Sarrebrück et des archives municipales de Sarrelouis ${ }^{99}$. Il y souligne l'intérêt d'envoyer régulièrement des historiens français dans 
les régions rhénanes, en particulier à Cologne, Coblence, Mayence, Spire, Darmstadt et Düsseldorf, et de développer des échanges professionnels, nés de la guerre, en envoyant les archivistes français se rendre compte de la qualité d'organisation des grands dépôts allemands ${ }^{100}$. Le second rapport Schmidt est adressé au commissaire de la République contrôlant l'administration des territoires rhénans, qui donne des instructions aux étatsmajors des armées d'occupation pour collecter les travaux historiques menés dans leur zone sur la première occupation française et accepte en outre de prendre à sa charge les frais d'une bourse spéciale, ouverte aux jeunes diplômés de l'École des chartes, souhaitée par la direction des Archives, afin de poursuivre les travaux de bibliographie des régions rhénanes et d'identification des fonds d'archives relatifs à la première occupation française ${ }^{101}$.

Au cours de ses deux voyages de 1919 en région rhénane, qu'avait donc observé Charles Schmidt?

Découvrant, en janvier 1919, les archives grand-ducales du Luxembourg - le Grand Quartier général du maréchal Foch est installé à Luxembourg -, Schmidt signale que les papiers du département français des Forêts (1795-1814) sont classés et inventoriés. Passant ensuite par les archives municipales de Trêves, il met en évidence que les archives de la préfecture française de la Sarre ont été transférées, de 1818 à 1823, aux Archives de la province de Coblence et que les papiers de la Société des recherches utiles, créée en 1801, sont conservés au Musée provincial.

En février 1919, Schmidt constatait que les Archives d'État de Coblence conservaient les archives des pays conquis (1794-1802) et des départements de la Sarre et de Rhin-etMoselle (1802-1814), en état intact et inventoriées depuis 1903 pour la période française ${ }^{102}$ . De retour les 22-23 juillet, il prend connaissance de la notice sur les Archives d'État dressée par un jeune élève de l'École des chartes, J. de Font-Réaulx, secrétaire d'étatmajor de la $\mathrm{X}^{\mathrm{e}}$ armée à Coblence, et réclame au docteur Bär, directeur, des inventaires complets et détaillés des fonds français de son dépôt; devant sa résistance ${ }^{103}$, Langlois prévoit, en août, d'envoyer à Coblence un jeune chartiste résumer et traduire en français les extraits des inventaires analytiques du dépôt mentionnant des fonds français ${ }^{104}$. Schmidt avait aussi dénoncé le cantonnement, dans les bureaux même des Archives d'État, de soixante individus «que l'armée américaine a déclarés indésirables et dont elle a demandé la surveillance », obligeant à fermer le dépôt au public ; Bär convainc Schmidt et Langlois de dénoncer la situation auprès du contrôleur général de l'administration des Territoires rhénans, qui demande au général commandant des forces américaines que l'accès du public des Archives de Coblence soit restauré, notamment en raison de la présence d'archives françaises ${ }^{105}$.

Bien que l'ancien département du Mont-Tonnerre ait eu son chef-lieu à Mayence, Schmidt constate en janvier 1919, aux Archives municipales de Mayence, que le fonds du département français est réparti entre Darmstadt (archives du grand-duché de Hesse Darmstadt) et Spire (archives du Palatinat bavarois) et que ne subsistent à Mayence que les délibérations municipales et la correspondance de la Ville durant la période française, alors en cours de dépouillement par J. Estienne, archiviste départemental de la Drôme, mobilisé comme secrétaire d'état-major de l'armée du général Mangin ${ }^{106}$. De retour en juillet 1919, il observe que, également mobilisés à l'état-major de la X ${ }^{\mathrm{e}}$ Armée, L. Royer, bibliothécaire à la Bibliothèque nationale, et J. de Font-Réaulx, chartiste, ont pu poursuivre l'inventaire sommaire du fonds français par Estienne, envoyer au Comité des 
travaux historiques des copies de documents et valoriser ces fonds dans le Bulletin de renseignements de la $\mathrm{X}^{\mathrm{e}}$ armée $\mathrm{e}^{107}$.

Quant aux Archives provinciales de Spire, visitées en janvier et en juillet 1919, elles conservaient les archives, très nombreuses, relatives à l'occupation française du Palatinat sous la Révolution et l'Empire, dont le classement et l'inventaire sont confiés au directeur adjoint lui-même ${ }^{108}$. L'inventaire des fonds des administrations françaises conservées aux Kreisarchiv de Spire, œuvre du Dr Pfeiffer, est d'ailleurs transmis par L. Royer, déjà cité, à Langlois le 10 juin 1919, suivi, en août 1919, d'un inventaire manuscrit des « documents d'archives relatifs à la domination française dans le Palatinat de 1792 à 1814 ", placé dans la salle de travail des Archives nationales ${ }^{109}$.

Schmidt se rend aux Archives municipales de Wiesbaden en janvier 1919, constatant l'existence de quelques documents issus des fonds des principautés de Kirchheim Bolanden, Hombourg ou relatifs à Sarrebrück, pour la période antérieure à $1815^{110}$.

Les archives de la région de la Sarre constituent un cas particulier. «Si le pays de la Sarre revient à la France, des problèmes se poseront au sujet des archives à réclamer en même temps. Mais ce problème ne saurait être traité [...] que lorsque les nouvelles frontières auront été dessinées ", écrit Langlois au ministre de l'Instruction publique début $1919^{111}$. Prussienne en 1814-1815, la région de la Sarre fut, à la suite du traité de Versailles en 1919, séparée pendant quinze ans de l'Allemagne et confiée à la Société des Nations, la propriété des gisements houillers, exploités à partir de 1871, étant transférée à la France. Langlois se préoccupe très tôt du sort des archives des villes de la région de la Sarre et, dès novembre 1918, fait écrire au ministre de la Guerre pour qu'à l'instar de la mission d'inspection que le Gouvernement allemand avait, en 1870, instaurée dans les Archives de la Meurthe, à Nancy, il pût envoyer un professionnel des archives dans les dépôts d'archives de la région de la Sarre, pour empêcher toute soustraction documentaire ${ }^{112}$. Schmidt visite d'ailleurs les Archives municipales de Sarrebrück à deux reprises. Lors de sa tournée de janvier 1919, il cherche en vain à consulter le fonds des mines fiscales, notamment pour repérer l'atlas minier établi par ordre de Montalivet en 1801 ; en juilletaoût 1919, il ne repère pas d'archives intéressant l'occupation française de 1792-1814, mais alerte Langlois sur les conditions d'application du traité de paix (chapitre relatif au régime de la Sarre, paragraphe 20), selon lequel l'Allemagne devra remettre au Gouvernement du bassin de la Sarre les documents officiels et archives se rapportant au territoire de ce bassin et aux droits de ses habitants ${ }^{113}$. Aux archives de Sarrelouis, visitées lors de sa seconde tournée, Schmidt constate que les vestiges des archives de la période française (1680-1915) sont conservés au secrétariat de la mairie, non classés, non inventoriés, et invite Langlois à les signaler au colonel Strohl, chef du $2^{\mathrm{e}}$ bureau de la $\mathrm{X}^{\mathrm{e}}$ armée. N'ayant pu découvrir Darmstadt en janvier 1919, Schmidt demande au colonel Strohl, en juillet, d'envoyer J. de Font-Réaulx aux Archives d'État de Darmstadt, pour dresser l'inventaire, en français, du fonds du département du Mont-Tonnerre, réparti, après 1815 , entre Spire et Darmstadt ${ }^{114}$.

70 Aux Archives municipales de Cologne, Schmidt signale, en juillet 1919, la publication de l'inventaire des actes relatifs à l'administration française (1794-1814), par J. Hashagen, en 1914, et plusieurs fonds d'administrations allemandes existant à l'époque napoléonienne. Y croisant le jeune chartiste Courtet, secrétaire d'état-major, il lui propose de dépouiller, dans les fonds français, les documents relatifs à l'histoire religieuse, en attendant sa démobilisation ${ }^{115}$. Il visite aussi les Archives économiques de la région rhénowestphalienne (Rheinisch-Westfälisches Wirtschaftsarchiv), mises en valeur lors du premier 
congrès des Archives économiques (Cologne, octobre 1913) et dont il aimerait importer le principe en France, en particulier en Alsace ${ }^{116}$.

71 Schmidt conclut son rapport d'août 1919 en signalant l'examen nécessaire des archives de Düsseldorf dès la restauration de la circulation en Allemagne non occupée, du fait de la présence des archives de l'administration provisoire des pays entre Meuse et Rhin et du département de la Roër (1792-1814) ${ }^{117}$.

\section{Reconstituer les documents détruits}

Dès le 24 mars 1917, le ministre de l'Instruction publique avait transmis aux archivistes des régions envahies des mesures à prendre pour sauver les archives communales, et notamment les documents d'état civil, confiant une mission spécifique aux archivistes départementaux de l'Oise et de la Somme. De son côté, le Grand Quartier général s'était préoccupé assez tôt de préserver, sur le terrain, les documents paroissiaux, puis d'état civil, comme en témoigne la circulaire du 2 avril 1917 aux chefs de corps, déjà citée, sans doute d'une application un peu complexe en temps de guerre, mais dont il faut saluer l'existence ${ }^{118}$. Pourtant, l'état civil français, comme l'ont attesté les milliers de fiches de recensement des pertes transmises par les archivistes départementaux du Nord-Est, a été durement touché par la Grande Guerre. Il s'agissait donc d'encadrer par une loi la reconstitution des actes et archives détruits dans les départements par suite des événements de guerre. La discussion fut longue. Un premier projet de loi, en douze articles, daté du 2 mars 1920, est examiné à la séance du 9 mars 1920 de la Chambre des députés, et envoyé à la commission de la Législation civile et criminelle. Son rapport, associé à un nouveau projet de texte, en onze articles, est présenté par Pierre Constans, député de l'Aude, à la séance du 3 décembre 1920 de la Chambre des députés, suivi d'un rapport complémentaire, présenté à celle du 22 décembre. Enfin votée le 15 décembre 1923, la loi tant attendue, constituée de 10 articles, énumère et traite le cas des principaux documents servant de preuve dans l'environnement administratif et réglementaire français du temps: les actes de l'état civil, les livrets de famille, les documents relatifs aux travaux publics, les actes notariés, les actes authentiques délivrés par les conservateurs des hypothèques, les extraits analytiques et notes d'audience des magistrats. Elle cherche à pallier leurs lacunes, sanctionnant toute rétention d'information et installant les tribunaux compétents, la tarification et l'imputation des coûts de ces reconstitutions ${ }^{119}$.

\section{Que faire des archives produites, entre 1914 et 1918 , par les services de guerre?}

73 Il reste à s'interroger, à propos de la gestion des archives durant la Grande Guerre, sur le sort du patrimoine documentaire produit par l'administration française du fait même de la guerre. Les démarches ponctuelles, menées en 1914-1915, de collecte des fiches d'histoire locale des instituteurs et des affiches de guerre, déjà évoquées, paraissent bien dérisoires au député Claude Cochin, qui fait paraître, dans La Revue hebdomadaire du 7 juillet 1917, une intéressante alerte sur l'urgence de rassembler des documents pouvant faire preuve et témoignage d'un événement historique sans précédent :

Ce que la meilleure partie de notre pays, avide de connaître, réclamera, c'est le

document objectif, l'ordre donné par le chef dans son texte original, le morceau de 
papier froissé, griffonné sur un coin de table, la petite feuille jaune du message téléphoné, le croquis topographique relevé en première ligne. L'avenir voudra voir la physionomie vraie de la guerre et non une image falsifiée par la rancune et l'intérêt. Quels sont les moyens que nous avons prévus pour satisfaire à cet immense besoin de savoir ? Dans une proposition très opportune, MM. Honnorat et Varenne ont invité le Gouvernement à procéder au classement et à la centralisation de tous les périodiques français et étrangers pouvant servir à l'histoire de la guerre, mais cette proposition a été déposée à la Chambre des députés le 22 décembre 1916 et n'est pas encore rapportée. Le ministre de l'Instruction publique avait également, à la demande du Comité des travaux historiques, signalé au personnel de l'Enseignement, aux sociétés savantes, aux correspondants du ministère, l'intérêt qu'il y aurait à consigner par écrit les témoignages oraux de l'esprit public, de la vie morale et de la vie économique de la France pendant la guerre. Quant aux documents d'archives, à proprement parler, on y songe peu ${ }^{120}$ encore reçu de versements de services de guerre, rendant l'exercice descriptif et prospectif peu aisé. Les uns mirent en avant l'intérêt de conserver les sources d'une histoire locale, voire anecdotique, de la guerre, d'autres, les sources de l'histoire économique (industrie, commerce, agriculture, main-d'œuvre), mettant par exemple en avant la valeur documentaire des archives des Bureaux permanents des céréales. Il est insisté sur le fait que les documents datant d'avant 1914, donc du temps de paix, ne renseignent que très incomplètement sur la vie économique de la France et que c'est sans doute du fait de l'état de guerre que les documents de la période 1914-1918 constituent la meilleure documentation pour l'histoire économique du début du $\mathrm{XX}^{\mathrm{e}}$ siècle (ressources $\mathrm{du}$ sol, industrie, commerce, transports, consommation). Beaucoup, tel l'archiviste girondin Brutails, demandaient que l'on surseoie à toute décision, trop hâtive, de tri et de

$1^{\circ}$ ) Ouels sont les services de guerre dont le fonctionnement a été confié à agents de la préfecture? Quels sont les autres?

$2^{\circ}$ ) Parmi les papiers des services de guerre de la préfecture, quels sont ceux qui paraissent avoir de l'intérêt pour l'histoire, et quand pourront-ils être versés dans

dès la clôture des opérations au plus tard?

$4^{\circ}$ ) Les papiers des services de guerre relevant d'administrations autres que la préfecture contiennent aussi des documents utiles à conserver. Quels sont ceux dont le versement aux archives départementales semble indiqué, et à qui faut-il les demander ${ }^{123}$ ?

Or, à l'automne 1919, beaucoup de services d'archives départementales n'avaient pas 
destruction: «Les événements survenus pendant ces dernières années présentent un intérêt tellement exceptionnel qu'il serait regrettable, ce me semble, de décider a priori que telles séries de documents seront détruites. Je serais d'avis que tout fût conservé pendant un délai à déterminer et que l'on procédât aux éliminations plus tard, avec une extrême circonspection. »

En complément de cette vaste enquête d'octobre 1919 peut être citée aussi la demande ministérielle faite aux archivistes départementaux de l'Aisne, de la Marne, de Meurthe-etMoselle, de la Meuse, du Nord, de l'Oise, du Pas-de-Calais, de la Somme et des Vosges, les seuls concernés, de s'intéresser, à l'instar de l'archiviste départemental des Ardennes, aux documents des archives communales relatifs aux rapports avec l'ennemi durant l'occupation ${ }^{124}$.

78 Mais ce n'est que dix ans plus tard, par une seconde enquête diffusée le 31 octobre 1928, qu'un recensement national fut relancé, motivé par la saturation croissante des dépôts. Ces deux enquêtes globales de 1919 et 1928, riches des réponses de 77 départements et de la collaboration de 98 archivistes des départements de la métropole, de Constantine et d'Oran, ont pour avantage d'identifier les grands gisements d'archives administratives sur la guerre 1914-1918, versées ou non aux services d'archives, et d'en énumérer les principaux producteurs :

I. Services de la préfecture.

1. Ministère de l'Intérieur : service des réfugiés, service des allocations aux familles des mobilisés, service des allocations temporaires aux petits retraités de l'État.

2. Ministère de l'Agriculture et $\mathrm{du}$ Ravitaillement: service de la carte d'alimentation, bureau permanent des céréales, bureau du contrôle des stocks, comité de taxation des denrées, office départemental des essences et du pétrole, comité départemental de répartition des sucres, commission départementale de la main-d'œuvre agricole, sous-comité départemental d'action économique, comité départemental d'action agricole pour la mise en culture des terres abandonnées.

3. Ministère de la Guerre: contrôle de la main-d'œuvre agricole, commission départementale d'évaluation des réquisitions.

4. Ministère du Travail et de Prévoyance sociale.

5. Ministère de l'Instruction publique: office départemental des pupilles de la Nation.

II. Autres services.

1. Office départemental des charbons.

2. Administrations militaires: guerre (régions ou subdividions de région, corps, bureaux de recrutement, censure militaire, contrôle télégraphique, bureaux centraux de renseignement de la police militaire), marine militaire, intendance militaire (réquisitions, ravitaillement de l'armée, ravitaillement civil, maind'œuvre), direction des Forges, sûreté générale (commissariats spéciaux, centres de rapatriement).

3. Chambres de commerce.

4. CEuvres de guerre.

79 En mars 1939 enfin, Jean Hubert fut en mesure de lancer la synthèse de la masse de réponses reçues (identification des services producteurs, cotation, classement interne, état sanitaire, délais de conservation, modalités de tri) ${ }^{125}$, rapport important qui déboucha sur l'instauration de règles générales de classement et de principes de triage avant destruction des "papiers des services de la guerre 1914-1918», diffusés par circulaire du 18 juillet 1941, en plein nouveau conflit mondial ${ }^{126}$. Dans le but de désaturer les dépôts d'archives départementaux, un état très détaillé des documents provenant des services de la guerre 1914-1918 susceptibles d'être supprimés ${ }^{127}$ était adjoint à cette 
circulaire de 1941, que plusieurs services d'archives départementaux s'employèrent à appliquer à l'issue de la Seconde Guerre mondiale et durant le troisième quart du $\mathrm{XX}^{\mathrm{e}}$ siècle.

Le fonds d'archives de la direction des Archives, conservé aux Archives nationales, fournit un matériau exceptionnellement dense pour analyser le réseau des archives au moment de la mobilisation et de l'entrée en guerre, le fonctionnement, souvent dégradé, instauré en temps de guerre, les opérations de sauvegarde in situ ou d'évacuations, plus ou moins massives, des archives au beau milieu des tensions politico-militaires de 1914 et 1917-1918, enfin, les besoins nés de l'après-guerre (réparations des dommages, revendications, reconstitutions documentaires et gestion des archives produites par les services instaurés entre 1914 et 1918). Sans conteste, la narration qu'il permet mériterait d'être nuancée, précisée et enrichie, après confrontation avec les sources analogues conservées, à l'échelon territorial, dans chaque service d'archives départementales et dans nombre de services d'archives communales (correspondance avec le ministère et avec l'administration locale, plans d'actions, carnets et agendas de l'archiviste départemental, exceptionnellement conservés...). Les responsables de ces services ont bien souvent eu le sentiment de favoriser le travail des historiens à venir, en conservant ainsi les témoignages précieux du fonctionnement de leur institution patrimoniale face à la guerre. Achevant son rapport annuel de 1915, Marius Barroux, archiviste de la Seine, exprime parfaitement cette idée: "Quelque simples et sommaires que soient les renseignements qui précèdent, ils ne manqueront sans doute pas d'offrir plus tard un certain intérêt, si l'on considère que les services d'archives sont de ceux, assez rares, qui ont une histoire $»^{128}$.

\section{ANNEXES}

Annexe I

«Relevé chronologique des mesures prises pour sauvegarder les archives départementales, communales et hospitalières ", édition d'une note manuscrite de la direction des Archives [vers le 15 juin 1918] [Arch. nat., AB XXXI/356].

AISNE

M. Broche, archiviste départemental mobilisé, remis à la disposition du préfet, a dressé et envoyé à la direction des Archives: $1^{\circ}$ ) un état des dommages subis par les archives communales dans la partie du département libérée dès septembre $1914 ; 2^{\circ}$ ) un état des archives communales déposées à la sous-préfecture de Château-Thierry; $\left.3^{\circ}\right)$ unétat des archives communales de la partie du département libérée en 1917, sur lesquelles des renseignements ont pu être recueillis.

De cette statistique, il résulte que, si dans beaucoup de localités, on n'a pas jugé utile de déplacer les archives, dans d'autres, plus ou moins maltraitées, on a transporté ce qu'on a pu en sauver soit aux Archives nationales, soit à Noyon, soit à Amiens, soit à Château-Thierry. 
Les archives anciennes de l'hospice de Soissons ont été évacuées sur Oulchy-le-Château et y sont restées.

Lors de l'évacuation de Château-Thierry, le 31 mai 1918, les archives centralisées dans cette ville ont été embarquées sur une péniche et dirigées sur Orléans.

Le 10 juin 1918, une communication du préfet de Seine-et-Oise a fait connaître que les archives de Saint-Pierre-Aigle contenues en trois caisses et confiées au facteur de la localité, viennent d'être déposées par lui à la mairie de Saint-Ouen-l'Aumône (Seine-et-Oise).

MARNE

Le 20 avril 1918, le préfet rend compte que l'archiviste municipal, mobilisé, remis à sa disposition, a fait descendre en caves plus de 500 cartons des séries $G$ et $H$. Les registres de délibérations de l'époque révolutionnaire, les documents les plus importants des séries modernes et les plans cadastraux d'une dizaine de communes.

On a descendu dans les caveaux de l'hôpital de Châlons les archives anciennes avec les parties les plus intéressantes $\mathrm{du}$ fonds moderne.

Les Archives de la Marne, ajoute le préfet, abritent l'état civil de Reims, les archives de la mairie et de la justice de paix de Suippes, du bureau militaire de Reims, celles d'un grand nombre de communes rurales, plusieurs caisses d'archives des agents financiers de l'arrondissement, les papiers des commissions des dommages de guerre, ceux du comité ardennais, des commissariats spéciaux de Reims et de Châlons, 45 cartons des archives de la sous-préfecture de Saint-Menehould, etc., etc.

On a dirigé successivement sur Épernay puis sur Chartres divers dépôts d'archives communales.

Le 25 avril 1918, le préfet rappelle qu'une partie importante des archives communales de Châlons a été déposée en 1916 aux Archives départementales de l'Aube.

Le 29 mai 1918, le préfet annonce que les papiers déposés dans les caves souffrent de l'humidité et qu'en conséquence, il va en transporter les parties les plus fragiles et les plus essentielles à Lyon, suivant les indications de la direction des Archives. Le convoi comportera aussi des documents des archives municipales de Châlons; il se fera par wagons plombés.

Reims. - Sous la direction de M. Loriquet, archiviste honoraire du Pas-de-Calais, et Robert, archiviste municipal de Reims, on a transféré dès 1917 aux Archives nationales les fonds d'archives départementales en dépôt à Reims, c'est-à-dire ceux de l'archevêché, du chapitre et des abbayes, une partie du fonds municipal, les registres paroissiaux, la collection Tarbé, tous les anciens plans, comprenant ensemble 17 caisses, 667 cartons moyens, 156 cartons longs, 48 registres, 49 paquets de registres, 134 liasses.

Déjà, en février 1917, sur les indications de M. le directeur des Archives, qui s'était rendu à Reims, M. Berland, archiviste de la Marne, avait ramené de Reims à Châlons tous les papiers anciens du greffe du tribunal, y compris les registres d'état civil antérieurs à 1800 des communes de l'arrondissement.

Enfin, les Archives nationales ont reçu directement et à plusieurs reprises des pièces éparses d'archives communales de la Marne, envoyées directement du front par l'autorité militaire. 
Le 3 mars 1917, le préfet rend compte que, sur invitation du ministre, il a fait emballer les archives départementales les plus précieuses en 20 caisses garnies de papier goudronné et qu'il les a fait diriger sur les Archives départementales de l'Aube.

On avait déjà descendu dans les caves du tribunal de commerce de Nancy plusieurs caisses de documents pris dans les séries $Q, S, T, U, V$. Une vérification récente a montré que ces caisses sont en bon état.

En février 1918, sur les indications de M. Vidier, inspecteur général des Archives, 372 registres de l'ancienne cour souveraine de Lorrraine qu'on avait déposés dans les caves de la cour d'appel de Nancy, ont été expédiés aux Archives nationales.

Une communication envoyée de Lyon au journal Le Petit Parisien et datée du 27 mai 1918 annonce que les archives municipales de Nancy ont été évacuées sur Lyon.

Lunéville. - 40 caisses de documents sont depuis 1916 dans une cave voûtée de l'hôtel-de-ville. Grâce aux précautions prises, ces caisses, fréquemment vérifiées, ne souffrent pas de l'humidité.

Toul. - La portion la plus importante des archives communales avait été mise dans des caisses à claire-voie et descendue dans les caves de l'hôtel-de-ville. Visitées par des rats, les caisses ont été remontées au rez-de-chaussée. On assure qu'elles ne courent aucun danger.

MEUSE

16 août 1915. Le sous-préfet de Verdun a recueilli à la sous-préfecture et mis en caisses dans des salles voûtées les papiers d'une dizaine de communes. Les documents anciens et, parmi les modernes, les plus précieux des archives communales de Verdun ont été déposés dans les caves de l'hôtel-de-ville; les registres de l'état civil, dans les caves du palais de justice.

15 septembre 1915. Le sous-préfet de Commercy a pris des mesures pour préserver les archives d'une quinzaine de communes $\mathrm{du}$ front, dans son arrondissement.

17 octobre 1915. Dès septembre, les archives anciennes de la ville et de l'hospice de Verdun ont été expédiées à Riom. Les registres d'état civil de l'arrondissement (exemplaire du greffe) ont été transportés au palais de justice de Dijon.

15 janvier 1916. Une bonne partie des archives des communes situées dans la zone des combats ont été préservées par les sous-préfets de Verdun et de Commercy, la plupart dirigées sur les Archives départementales à Bar-le-Duc.

10 mars 1916. Le sous-préfet de Verdun a fait transporter en 75 caisses aux Archives départementales les papiers modernes de la mairie de Verdun (les anciens étant déjà à Riom) ; plus 25 caisses de registres et de pièces de comptabilité de la recette des finances ; plus les registres d'état civil, pièces cadastrales et autres des communes avoisinant le front, sans parler d'une cinquantaine de colis déjà déposés et de ceux qui continuent à arriver tous les jours.

En 1916, on a pu retirer de la sous-préfecture de Verdun un certain nombre d'ouvrages administratifs et de liasses d'archives et les transporter en 30 caisses, sacs et cartons aux Archives départementales de la Meuse.

À la fin de l'année 1917, les Archives départementales ont expédié par wagons plombés aux Archives départementales de la Gironde 91 caisses de documents comprenant entre autres : collection Buvignier ; registres de vente de biens nationaux ; registres de délibérations des assemblées départementales et conseils généraux jusqu'à l'époque de leur impression (1840): 
cartulaires des séries $H, B, E$ : registre des arrêtés des préfets ; le fonds de la chambre des comptes de Bar, etc.

Les Archives nationales ont reçu, d'autre part, une certaine quantité de documents d'archives communales de la Meuse envoyés directement du front par les soins de l'armée.

NORD

Octobre 1917. Mission de M. Langlois dans le Nord et le Pas-de-Calais.

14 mai 1918. Le préfet du Nord communique un rapport du directeur de l'Enregistrement faisant connaître qu'il vient de répartir entre Évreux et Louviers les documents des bureaux d'enregistrement et des conservations d'hypothèques de la portion non occupée du département du Nord.

OISE

1917. M. Roussel, archiviste départemental, chargé de s'enquérir de l'état des archives des localités de l'Oise récupérées, a envoyé plusieurs rapports contenant l'état de ces dépôts. Le plus important, celui de Noyon, était intact. Diverses mesures de sauvetage ont été prises par lui conjointement avec la prévôté des armées.

16 avril 1918. En réponse à une question posée par la direction des Archives, l'archiviste départemental demande des instructions pour l'évacuation éventuelle d'une portion de son dépôt.

Le 18, on le presse d'évacuer, sur Le Mans, ou sur Nîmes, les archives départementales et sur Lyon les archives communales et hospitalières de Compiègne.

Le 19, l'archiviste départemental fait savoir que les archives communales de Compiègne ont été évacuées sur Enghien-les-Bains, sous la garde d'une employée de la mairie. Le sous-préfet a mis en lieu sûr les documents les plus utiles et les plus précieux des archives de la sous-préfecture.

Le 13 mai, le sous-préfet annonce que les archives hospitalières sont parties pour Aire-sur-l'Adour, où les services de l'hôpital les avaient précédées.

Le 7 juin, l'archiviste départemental fait savoir que, dans la nuit du 5, une torpille et une bombe, tombées dans la cour de la préfecture, ont causé des dégâts matériels aux archives, mais qu'aucun document n'a été atteint. Les 150 caisses d'archives emballées sont intactes; elles vont partir pour Nîmes.

Les Archives natoinales tiennent en dépôt un certain nombre de documents d'archives communales de l'Oise envoyées directement du front par l'autorité militaire.

PAS-DE-CALAIS

20 juillet 1915. Le ministre donne à M. Langlois la mission d'aller à Arras prendre les mesures nécessaires pour assurer la sauvegarde de ce qui subsiste des archives départementales.

M. Langlois s'étant rendu à Arras les 22 et 23 juillet, il a été décidé d'évacuer sur les Archives nationales ce qui restait des archives départementales et des archives communales d'Arras, le tout pouvant former un convoi de 18 wagons (y compris des manuscrits à déposer à la Bibliothèque nationale).

Août 1915. Le déménagement et le transfert ont été faits par les soins de l'archiviste départemental, M. Flament, capitaine du service armé pour qui on avait obtenu un congé d'un mois. L'autorité militaire avait mis à sa disposition 92 camions automobiles pour se rendre d'Arras à Duisans où on chargeait sur rails la nuit. L'opération a duré 17 jours et 17 nuits. Les documents ont été répartis au 
palais Soubise entre les caves et certaines portions disponibles du rez-de-chaussée. En même temps, M. Flament faisait transporter à Boulogne, nouveau siège de la préfecture, 2210 cartons d'affaires courantes.

Novembre 1915. L'opération précédente a été complétée par la mise en sûreté des archives hospitalières d'Arras et des documents de l'annexe des Archives départementales.

6 avril 1917. Le préfet rend compte des mesures qu'il a prises pour faciliter, d'accord avec la mission française près l'armée anglaise, le sauvetage des archives des communes récemment récupérées.

Octobre 1917. Mission de M. Langlois dans le Nord et le Pas-de-Calais.

18 octobre 1917. Le cabinet du ministre demande un sursis d'un mois pour l'archiviste municipal de Calais pour lui permettre de retirer les archives de la ville du local où elles sont en danger.

8 novembre. Sursis accordé.

29 novembre. Le maire de Calais rend compte que les archives ont été transférées dans le sous-sol de la tour du nouvel hôtel-de-ville. L'opération demandant plus d'un mois, il demande une prolongation du sursis accordé à l'archiviste. (Refusé le 29 décembre).

Le 11 mai 1918. Le maire de Calais redemande l'archiviste pour trier les archives à évacuer. Le 30 mai, le ministre de la Guerre refuse!

Boulogne. - 6 mars 1918. Le maire fait connaître qu'il avait déposé dans une cave voûtée et sèche 20 caisses d'archives anciennes. L'opération se continue pour les archives révolutionnaires, l'état civil, les titres de propriété communales, les délibérations et arrêtés de la municipalité. Les archives hospitalières vont être placées dans des caisses doubles de fer blanc et descendues dans des caves.

Saint-Omer. - 31 mai 1918. Le maire télégraphie demandant une localité moins éloignée que Lyon ou Nîmes pour évacuer les archives. Le $1^{\text {er }}$ juin, on lui indique Bordeaux.

Le 9 juin 1918, le même télégraphie que le bibliothécaire est démissionnaire et il demande qu'on lui envoie quelqu'un de Paris pour surveiller et convoyer les archives de Bordeaux. On lui reprend, le 10 juin, qu'on ne dispose de personne.

Les Archives nationales ont reçu directement du front par les soins de l'autorité militaire quelques épaves des archives de Carency et de Loos.

SOMME

21 juillet 1917. L'archiviste départemental rend compte des mesures prises pour assurer le sauvetage des archives dans les localités récupérées de la Somme, notamment à Péronne, Roye, Ham, Nesle; tout ce qui n'a pu être laissé sur place a été centralisé dans un local spécial à Amiens.

27 mars 1918. L'ordre ayant été donné d'évacuer la population civile d'Amiens dans la journée, l'archiviste départemental a fait charger le lendemain, sur les deux seuls camions qu'il avait pu obtenir, quelques-unes des caisses préparées par lui depuis longtemps et renfermant les documents les plus précieux de son dépôt. Ces caisses ont été dirigées sur Rouen.

10 mai 1918. L'archiviste départemental n'étant plus retourné à Amiens, le commandant Welter, du cabinet civil du ministre de la Guerre, a fait savoir qu'il venait de se rendre dans cette ville pour s'occuper personnellement de l'évacuation des archives. Avec l'aide de plusieurs centaines de Marocains, tout sera terminé dans quelques jours.

Les Archives nationales ont reçu en dépôt des autorités militaires du front quelques documents d'archives communales de la Somme. 
VOSGES

27 mai 1918. Le préfet fait connaître que le 29 avril, il a fait expédier sur les Archives départementales de l'Hérault, 70 caisses de documents, dont 56 pour les archives départementales, 4 pour la bibliothèque d'Épinal, 9 pour les archives anciennes de cette ville, 1 pour les documents les plus précieux de Saint-Dié.

\section{NOTES}

1. - Lire par exemple, parmi les publications récentes, pour l'Oise : DITTE, Christelle. « Les archives dans la guerre dans l'Oise en 1914-1918 ». Dans 1914-1918. L'Oise dans la Grande Guerre [actes du colloque tenu à Noyon, 24-25 octobre 2008]. Beauvais : Conseil général de l'Oise, 2011, p. 193-199 ; pour la Somme : De SOLAN, Olivier. «Les archives de la Somme pendant la Première Guerre mondiale ». Dans Guerre et patrimoine artistique à l'époque contemporaine, [actes du colloque tenu à Amiens, 16-18 octobre 2011]. Amiens : Encrage Édition (coll. «Hier»), 2013, p. 71-93 ; et pour les Vosges : CHAVE, Isabelle. «Trois conflits, trois contextes, trois destinées. Le sort des fonds des Archives départementales des Vosges de 1870 à 1945 ». Dans Guerre et patrimoine artistique à l'époque contemporaine, ouvr. cité, p. 49-69.

2. - Arch. nat., sous-série AB/XXXI. Voir Archives du bureau, puis du service des Archives départementales, communales et hospitalières, puis du service technique de la direction des Archives de France (1854-1958). Répertoire numérique détaillé des sous-séries AB/XXXI (art. 1-405), AB/XXXI/A, AB/ $X X X I / B$ et $A B / X X X I / C$, par Laure Bories. Paris : Direction des archives de France, 1999, 66 p. Le secrétariat de la direction des Archives, qui n'avait que la charge des Archives nationales, comprit désormais, à partir du décret du 23 février 1897, deux services, le service des Archives nationales, dirigé par un secrétaire-adjoint, et le service des Archives départementales, dirigé par un autre secrétaire-adjoint. En 1903, ce secrétariat de la direction des Archives fut érigé au rang de section, dirigée par un sous-chef (jusqu'en 1908), puis un chef : Welvert. En 1912, la section du secrétariat devint la section des services administratifs, qui comprenait elle-même deux services, le secrétariat des Archives nationales et le service des Archives départementales, ce dernier confié à Robert Villepelet, archiviste venu du ministère de l'Instruction publique. Telle est la situation de l'encadrement des services d'archives constitués, en France, au moment où éclate la Première Guerre mondiale.

3. - Arch. nat., $\mathrm{AB} / \mathrm{XXXI} / 3$, procès-verbaux des séances de la Commission supérieure des archives (3 avril 1906-21 décembre 1933). Les séances du 27 juin 1914 et du 26 juin 1919 ne comportent aucune allusion à la tension politique, pour la première, ou aux conséquences du conflit, pour la seconde.

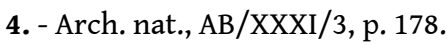

5. - Arch. nat., AB XXXI/356, note de Ch.-V. Langlois, directeur des Archives, au ministre de l'Instruction publique, 25 mai 1915. Certains bombardements touchèrent le quartier du Marais, tel celui de l'église Saint-Gervais en mars 1918.

6. - BARROUX, Marius. «Rapports annuels de l'archiviste [de la Seine]. Exercices 1913-1914 et 1914-1915 ». Tirés à part de la Bibliothèque de l'École des chartes, 1919, p. 3 [en ligne sur le site de l'École des chartes].

7. - BARROUX, Marius. « Rapports annuels de l'archiviste [de la Seine]. Exercices 1913-1914 et 1914-1915 ", déjà cité, p. 14.

8. - Arch. nat., $\mathrm{AB} X X X \mathrm{XI} / 356$, note de Ch.-V. Langlois au ministre de l'Instruction publique, 25 mai 1915.

9. - Arch. nat., A XXXI/356, note de Ch.-V. Langlois au ministre de l'Instruction publique, 10 avril 1915 : « dans 44 départements de l'Ouest, du Centre, du Sud-Est et du Midi, l'archiviste, en raison 
de son âge, est resté à son poste [...], mais dans 33 autres départements des mêmes régions, les dépôts départementaux ont été privés de leur archiviste, appelé sous les drapeaux ».

10. - Arch. nat., $A B X X X I / 43$, circulaire du ministre de l'Instruction publique et des Beaux-Arts aux préfets, 20 novembre 1914.

11. - Arch. nat., $A B X X X I / 43$, circulaire du ministre de l'Instruction publique, des Beaux-Arts et des Inventions intéressant la défense nationale aux préfets, 27 septembre 1916.

12. - Arch. nat., $A B / X X X I / 3$, registre des séances de la Commission supérieure des archives (1906-1933), p. 178 : « Un des deux inspecteurs généraux est mobilisé [...]. Beaucoup d'archivistes, soit des Archives nationales, soit des Archives départementales, sont mobilisés. Il est donc difficile d'entreprendre l'étude d'une grande question ou de faire une grande enquête dans ces conditions ».

13. - Arch. nat., $\mathrm{AB} X X X \mathrm{XX} / 15$, « Rapport au ministre de l'Instruction publique et des Beaux-Arts sur le service des archives ( $1^{\mathrm{er}}$ mai 1916-1 ${ }^{\mathrm{er}}$ mai 1917) », par Ch.-V. Langlois, Journal officiel de la République française, 2 juin 1917, p. 4310 ; « [Idem] (1 ${ }^{\mathrm{er}}$ mai 1917-1 ${ }^{\mathrm{er}}$ mai 1918) », Journal officiel de la République française, 23 mai 1918, p. 4539 ; « [Idem] (1 $1^{\mathrm{er}}$ mai 1918-1 ${ }^{\mathrm{er}}$ mai 1919) », Journal officiel de la République française, 7 juin 1919, p. 5952.

14. - BARROUX, Marius. "Rapports annuels de l'archiviste [de la Seine]. Exercices 1913-1914 et 1914-1915 ", déjà cité, p. 43-44.

15. - Avec citation à l'ordre du régiment [Bulletin du ministère de l'Instruction publique, 24 février 1917].

16. - Arch. nat., $A B X X X I / 15$, « Rapport au ministre de l"Instruction publique et des BeauX-Arts sur le service des archives ( $1^{\mathrm{er}}$ mai 1917-1 ${ }^{\mathrm{er}}$ mai 1918) », déjà cité, p. 4539.

17. - Ceux de la Charente-Inférieure (Pandin de Lussaudière), de la Corrèze (Mathieu), de la Haute-Marne (Pierre Gautier) et du Pas-de-Calais (Flament, d'abord présumé disparu) [Arch. nat., $\mathrm{AB}$ XXXI/15, « Rapport au ministre de l'Instruction publique et des Beaux-Arts sur le service des archives (1 ${ }^{\mathrm{er}}$ mai $1917-1^{\mathrm{er}}$ mai 1918) », déjà cité ; « [Idem] (1 er $^{\mathrm{er}}$ mai 1918-1 ${ }^{\mathrm{er}}$ mai 1919) », déjà cité, p. 5953].

18. - BARROUX, Marius. "Rapports annuels de l'archiviste [de la Seine]. Exercices 1913-1914 et 1914-1915 ", déjà cité, p. 14.

19. - Arch. nat., $\mathrm{AB} X X X I / 356$, note de Ch.-V. Langlois au ministre de l'Instruction publique, 25 mai 1915.

20. - Arch. nat., $A B X X X I / 15$, « Rapport au ministre de l'Instruction publique et des Beaux-Arts sur le service des archives ( $1^{\mathrm{er}}$ mai 1918-1 ${ }^{\mathrm{er}}$ mai 1919) ", déjà cité, p. 5952.

21. - BARROUX, Marius. " Rapports annuels de l'archiviste [de la Seine]. Exercices 1913-1914 et 1914-1915 ", déjà cité, p. 4-5, p. 12.

22. - Arch. nat., $A B X X X I / 15$, « Rapport au ministre de l'Instruction publique et des Beaux-Arts sur le service des archives ( $1^{\mathrm{er}}$ mai 1916-1 ${ }^{\mathrm{er}}$ mai 1917) », déjà cité, p. 4311.

23. - Selon l'archiviste départemental de la Seine, à propos des demandes de communication enregistrées en 1914, « il convient d'insister, à raison de leur caractère exceptionnel, [sur] les demandes de certificats d'exemption du service militaire ou de tirage au sort, ou parfois encore d'inscription sur les listes de la Garde nationale ; à partir des hostilités, il y en a eu 2044, dont 1129 en août 1914 et 288 en septembre ; on peut noter, comme fait marquant dans les annales des archives, qu'on a reçu une centaine de demandeurs le jour même du 15 août 1914, et près de 200 le lendemain » [BARROUX, Marius. "Rapports annuels de l'archiviste [de la Seine]. Exercices 1913-1914 et 1914-1915 », déjà cité, p. 5].

24. - Dans son rapport de 1915, Marius Barroux note : « Les mentions de mariage à porter en marge des actes de naissance ont encore atteint le chiffre de 285. Comme le service comporte en fait un grand nombre de transmission de demandes ou d'extraits d'actes de l'état civil, il y a lieu de relever que 3400 pièces ont été adressées aux mairies pour transcription sur les registres de 
décès ou pour insertion de la mention "Mort pour la France", alors qu'il n'y avait eu avant la guerre, en 1912-1913, que 1220 de ces transcriptions » [Ibid., p. 13].

25. - Arch. nat., AB XXXI/15, « Rapport au ministre de l'Instruction publique et des Beaux-Arts sur le service des archives ( $1^{\mathrm{er}}$ mai 1916-1 ${ }^{\mathrm{er}}$ mai 1917$)$ ", déjà cité, p. 4311.

26. - « En présence des prix élevés qu'atteignent actuellement les vieux papiers, il y a intérêt à vendre tous ceux qui sont détenus inutilement par les divers services de l'État ». Le Temps, 5 juin 1916.

27. - Arch. nat., AB XXXI/24, note de Langlois au ministre de l'IP, 24 juillet 1917.

28. - Arch. nat., $\mathrm{AB} X X X I / / 43$, circulaire du ministre de l'Instruction publique et des BeauX-Arts aux préfets relative aux notes communales sur la guerre, 27 décembre 1914, à verser " dans la série $\mathrm{R}$, à la fin de laquelle elles formeront une subdivision spéciale sous la rubrique Événements militaires, Guerre de 1914, Notes communales. " La mention de cette circulaire sur les fiches d'histoire locale apparaît dans plusieurs rapports annuels d'archivistes départementaux de la période, tel celui de Barroux, pour la Seine, en 1914 [BARROUX, Marius. « Rapports annuels de l'archiviste [de la Seine]. Exercices 1913-1914 et 1914-1915 ", déjà cité, p. 4].

29. - Arch. nat., $\mathrm{AB} X X X I / / 43$, circulaire du ministre de l'Instruction publique et des Beaux-Arts aux préfets relative aux affiches de guerre, 18 janvier 1915. Aux Archives départementales, elles sont à placer en série $\mathrm{R}$, dans une subdivision commune avec les notes de guerre des instituteurs. Aux Archives nationales, ces affiches sont aujourd'hui conservées, sur le site de Paris, dans la sous-série $\mathrm{AD} / \mathrm{XXc}$ de la Bibliothèque historique.

30. - Aux Archives départementales des Vosges, voir en série R. Aux Archives de la Seine, lire les rapports de Marius Barroux : « [1914]. Dès le commencement des hostilités, je m’étais préoccupé de former la collection des affiches de l'administration préfectorale et des mairies. Une circulaire de la direction des Archives a invité les archivistes à centraliser dans leurs dépôts les affiches de guerre. Grâce à de nouveaux efforts, un grand nombre d'affiches ont déjà été réunies ; la préfecture de Police a bien voulu faire parvenir celles qui étaient apposées par ses agents. Quelques mairies joignent à leurs envois divers autres imprimés »; “ [1915]. Les Archives ont continué à recevoir des exemplaires de pièces diverses publiées par les communes depuis la guerre »; « [1916-1917]. Les mairies ont été invitées de nouveau à faire l'envoi de leurs affiches et à y joindre toutes autres publications concernant la guerre »; « [novembre 1918]. Les affiches et pièces diverses relatives à la guerre feront, dès qu'elle sera finie, l'objet d'une entrée globale » [BARROUX, Marius. « Rapports annuels de l'archiviste [de la Seine]. Exercices 1913-1914 et 1914-1915 », déjà cité, p. 14, p. 19-20, p. 30].

31. - L'archiviste départemental de la Seine l'évoque à deux reprises, dans son rapport de 1916-1917 : « Le service des archives a été chargé de procurer au nouveau musée de la Guerre [...] les documents imprimés émanés de la préfecture ou des administrations qui en relèvent et de cette mission est résultée l'occasion pour lui de recevoir un exemplaire des mêmes documents. Quelques autres lui ont été adressés manuscrits, tels un compte rendu de l'aide prêtée par l'École alsacienne aux Alsaciens-Lorrains. Il n'a pu cependant obtenir en double un document expressément destiné au Musée : une aquarelle de l'Association des mutilés » et dans celui de 1918 : «Des circulaires ont été adressées aux mairies de Paris pour leur rappeler ou leur expliquer qu'elles ont à adresser aux Archives, non seulement leurs publications, mais encore, si possible, celles des œuvres de l'arrondissement, puis, conformément à une instruction du ministre de l'Intérieur concernant le musée de la Guerre, toutes publications de leur administration » [BARROUX, Marius. « Rapports annuels de l'archiviste [de la Seine]. Exercices 1913-1914 et 1914-1915 », déjà cité, p. 19, p. 30].

32. - Arch. nat., AB XXXI/24, note de Ch.-V. Langlois au ministre de l'Instruction publique du 24 juillet 1917 en réaction à l'article de COCHIN, Claude. "Les archives et la guerre ». La Revue hebdomadaire, 7 juillet 1917, p. 64-75. 
33. - Arch. nat., $\mathrm{AB} X X X \mathrm{XX} / 43$, circulaire du ministre de l'Instruction publique et des Beaux-Arts aux préfets, 10 juin 1915. Les archivistes départementaux du Nord, des Ardennes et de l'Aisne, départements totalement envahis, ont été exclus de ce recensement.

34. - Arch. nat., $\mathrm{AB} X X X \mathrm{XX} / 356$, « Note de $\mathrm{M}$. Camille Bloch, inspecteur général, sur l'état des dépôts d'archives communales dans les départements de la zone des Armées et de la zone réservée », 12 août 1915.

35. - « Dans la plupart des communes voisines du front, des précautions ont été prises depuis longtemps pour la préservation des parties les plus précieuses des archives communales (état civil, cadastre et matrices, délibérations, etc.). Mais il se peut que ces précautions n'aient pas été prises partout » [Arch. nat., AB XXXI/43, circulaire du ministre de l'Instruction publique et des Beaux-Arts aux préfets demandant d'expédier à l'arrière, si nécessaire, les archives des communes menacées, 24 août 1915.

36. - «Instructions envoyées pour évacuation d'archives ", édition d'une note manuscrite de Ch.V. Langlois [Arch. nat., AB XXXI/356].

37. - Arch. nat., $A B X X X I / 15$, "Rapport au ministre de l'Instruction publique et des Beaux-Arts sur le service des archives ( ${ }^{\text {er }}$ mai 1916-1 $1^{\text {er }}$ mai 1917) », déjà cité, p. 4311-4312. Ibid., AB/XXXI/3, registre des séances de la Commission supérieure des Archives (1906-1933), séance du 23 juin 1917, p. 183. (Langlois y mentionne les mesures qu'il a fait prendre dès le 24 mars 1917 pour sauvegarder les archives des localités récupérées de l'Aisne, l'Oise, la Somme et le Pas-de-Calais).

38. - Arch. nat., $\mathrm{AB} X X X \mathrm{XX} / 15$, « Rapport au ministre de l'Instruction publique et des Beaux-Arts sur le service des archives ( $1^{\mathrm{er}}$ mai 1916-1 ${ }^{\mathrm{er}}$ mai 1917) », déjà cité, p. 4311. " Instructions envoyées pour évacuation d'archives ", note manuscrite de Ch.-V. Langlois [Arch. nat., AB XXXI/356].

39. - Arch. nat., $\mathrm{AB} X X X \mathrm{XX} / 15$, « Rapport au ministre de l'Instruction publique et des BeauX-Arts sur le service des archives (1 ${ }^{\mathrm{er}}$ mai 1917-1 ${ }^{\mathrm{er}}$ mai 1918)», déjà cité, p. 4539.

40. - « Instructions envoyées pour évacuation d'archives », note manuscrite de Ch.-V. Langlois [Arch. nat., AB XXXI/356].

41. - Arch. nat., $A B / X X X I / 66$, lettre de l'archiviste départemental de Meurthe-et-Moselle au directeur des Archives nationales, Nancy, 13 octobre 1919.

42. - Arch. nat., $\mathrm{AB} / \mathrm{XXXI} / 3$, registre des séances de la Commission supérieure des Archives (1906-1933), séance du 18 juin 1918, p. 185.

43. - Arch. nat., $\mathrm{AB} / \mathrm{XXXI} / 70$ : fiche des pertes des archives communales du Pas-de-Calais, 1919. Les vingt-trois communes sont Achiet-la-Grande, Baralle, Bertincourt, Beugny, Bourlon, Buissy, Cagnicourt, Écourt-Saint-Alein, Écourt-Saint-Quentin, Fampouy, Favreuil, Grincourt-lèsHavrincourt, Havrincourt, Inchy-en-Artois, Lagnicourt, Marquion, Morchies, Oisy-le-Verger, Sains-lès-Marquion, Sapignies, Saudemont, Vélu et Villers-lès-Cagnicourt.

44. - Arch. nat., AB/XXXI/66, lettre de l'archiviste départemental de Meurthe-et-Moselle, déjà citée, Nancy, 13 octobre 1919.

45. - Arch. nat., AB XXXI/356, lettre du président du Conseil, ministre de la Guerre (cabinet civil), au ministre de l'Instruction publique (direction des Archives), Paris, 8 janvier 1918.

46. - Arch. nat., $\mathrm{AB}$ XXXI/356, note du ministre de l'Instruction publique au ministre de la Guerre, $1^{\mathrm{er}}$ décembre 1917.

47. - « Je vous signale l'utilité de faire rechercher d'une façon toute spéciale, dans les communes nouvellement reconquises, les registres de l'état civil et les documents de toutes natures qui peuvent être ensevelis dans les ruines des mairies ou qui, provenant de la mairie, ont été dispersés dans le pays. Ces documents, si incomplets et détérioriés soient-ils, doivent être soigneusement conservés car ils serviront notamment à la reconstitution des actes de l'état civil dont la perte serait, pour les populations déjà éprouvées, la cause de nouveaux préjudices. Dans le même but, il convient de prendre également toutes mesures utiles pour sauvegarder les registres encore dans les paroisses. Il importe enfin de mettre à l'abri ce qui peut rester des minutes et des papiers de notaires, percepteurs et en général des officiers publics et 
fonctionnaires de l'État. En conséquence, toutes les fois que des documents de la nature de ce dont il s'agit seront découverts dans une localité ou dans un immeuble où ils ne sont pas en sécurité, l'officier commandant l'unité avertira la prévôté. La prévôté dressera un procès-verbal en double expédition relatant les circonstances et contenant un état descriptif de la découverte. Un exemplaire du procès-verbal sera adressé au prévôt d'armée pour être remis au préfet. L'autre exemplaire vous sera adressé et me sera par vous transmis. Si les documents ne peuvent être rassemblés sur place en lieu sûr, ils seront envoyés dans le plus bref délai possible au prévôt d'armée, qui en fera la remise au préfet. » [Arch. nat., AB XXXI/356, note de l'aide major-général Pont, aux armées, GQG, 2 avril 1917].

48. - «Instructions envoyées pour évacuation d'archives », note manuscrite de Ch.-V. Langlois [Arch. nat., AB XXXI/356].

49. - Ibid.

50. - Arch. nat., $A B / X X X I / 65$, télégramme du préfet de la Marne au directeur des Archives nationales, 2 janvier 1919 : « Reçu circulaire du 26 novembre, mais archiviste départemental parti le 28 à Lyon et Nîmes pour rapatriement huit wagons archives. Rentré à Châlons le 11 décembre, est assez sérieusement indisposé depuis ", et lettre du préfet de la Marne au directeur des Archives nationales, Châlons, 4 novembre 1919 : «En dehors des archives que certains maires mirent à l'abri dans le sud du département, le service des archives départementales évacua sur le Centre et le Midi plus de deux cents dépôts d'archives communales. Cette évacuation, à laquelle participèrent MM. les sous-préfets de Reims et d'Épernay, sauva du désastre une quantité considérable de documents d'archives importants ".

51. - Arch. nat., $A B X X X I / 15$, « Rapport au ministre de l'Instruction publique et des Beaux-Arts sur le service des archives ( $1^{\mathrm{er}}$ mai 1918-1 ${ }^{\mathrm{er}}$ mai 1919) », déjà cité, p. 5953.

52. - Arch. nat., $A B / X X X I / 3$, registre des séances de la Commission supérieure des Archives (1906-1933), p. 185.

53. - Arch. nat., AB XXXI/15, « Rapport au ministre de l"Instruction publique et des BeauX-Arts sur le service des archives (1 $1^{\mathrm{er}}$ mai 1918-1 ${ }^{\mathrm{er}}$ mai 1919) ", déjà cité, p. 5952.

54. - Arch. nat., $\mathrm{AB} / \mathrm{XXXI} / 3$, registre des séances de la Commission supérieure des Archives (1906-1933), p. 187.

55. - Arch. nat., AJ /52 / 440, dossier III, rapport de juin 1918 sur les archives à évacuer au cas où l'École serait fermée.

56. - BARROUX, Marius. "Rapports annuels de l'archiviste [de la Seine]. Exercices 1913-1914 et 1914-1915 ", déjà cité, p. 25-26. « Il a fallu installer des services et recevoir le public dans le dépôt même, au rez-de-chaussée de l'aile droite, où sont conservées les archives de l'état civil. »; « Le nombre des documents préparés depuis 1914 pour être évacués rapidement ou déposés dans le coffre-fort avait été un peu augmenté ; on avait ainsi retiré de quelques séries très modernes, comme celle des versements de la direction du Personnel, les dossiers de certains fonctionnaires tels que Verlaine, Samain, Charles-Louis Philippe, curieux notamment par le fait qu'ils renferment souvent des compositions remises par ces hommes de lettres lors d'examens administratifs. "

57. - Arch. nat., $\mathrm{AB}$ XXXI/15, « Rapport au ministre de l'Instruction publique et des Beaux-Arts sur le service des archives ( $1^{\mathrm{er}}$ mai $1917-1^{\mathrm{er}}$ mai 1918) ", déjà cité, p. 4539. Dans plusieurs départements, en 1920 encore, l'archiviste doit consacrer une partie de son temps à des services de guerre non liquidés, tels que celui des réfugiés [Arch. nat., AB XXXI/15, « Rapport au ministre de l'Instruction publique et des Beaux-Arts sur le service des archives ( $1^{\mathrm{er}}$ mai $1919-1^{\mathrm{er}}$ mai 1920) ", par Ch.-V. Langlois, Journal officiel de la République française, 28 mai 1920].

58. - Ariège, Aube, Calvados, Charente-Inférieure, Corrèze, Corse, Côtes-du-Nord, Drôme, Isère, Haute-Marne, Pas-de-Calais, Haute-Savoie, Seine-et-Marne, Deux-Sèvres, Somme, Var, Vienne, ainsi que les trois départements jadis annexés : Moselle (Arbois de Jubainville), Bas-Rhin (Eckel) 
et Haut-Rhin (Waldner) [Arch. nat., AB XXXI/15, « Rapport au ministre de l'Instruction publique et des Beaux-Arts sur le service des archives ( $1^{\mathrm{er}}$ mai $1919-1^{\mathrm{er}}$ mai 1920)», déjà cité].

59. - Arch. nat., AB XXXI/15, « Rapport au ministre de l'Instruction publique et des Beaux-Arts sur le service des archives ( $1^{\mathrm{er}}$ mai 1918-1 ${ }^{\mathrm{er}}$ mai 1919) », déjà cité, p. 5952 : « après le 11 novembre, nos caisses sont revenues de Bordeaux en parfait état ». Le musée des Archives nationales rouvre le dimanche 19 octobre 1919 ; au $1^{\mathrm{er}}$ mai 1920, il avait accueilli, les jeudis et dimanches, 2150 visiteurs [Arch. nat., AB XXXI/15, « Rapport au ministre de l'Instruction publique et des BeauxArts sur le service des archives (1 ${ }^{\mathrm{er}}$ mai 1919-1er mai 1920) », déjà cité].

60. - Arch. nat., AB XXXI/15, « Rapport au ministre de l'Instruction publique et des Beaux-Arts sur le service des archives ( ${ }^{\mathrm{er}}$ mai 1918- $1^{\mathrm{er}}$ mai 1919) », déjà cité, p. 5954.

61. - Arch. nat., AB XXXI/15, « Rapport au ministre de l'Instruction publique et des Beaux-Arts sur le service des archives ( $1^{\text {er }}$ mai 1918- $1^{\text {er }}$ mai 1919) », déjà cité, p. 5954.

62. - Arch. nat., $A B X X X I / 15$, « Rapport au ministre de l'Instruction publique et des BeauX-Arts sur le service des archives ( $1^{\mathrm{er}}$ mai 1918- $1^{\mathrm{er}}$ mai 1919) », déjà cité, p. 5954, note 1 ; AB XXXI/356, Note sur les stipulations à insérer dans le traité de paix, en ce qui concerne les archives, [1919]; $\mathrm{AB}$ XXXI/15, « Rapport au ministre de l'Instruction publique et des Beaux-Arts sur le service des archives (1 ${ }^{\mathrm{er}}$ mai $1919-1^{\mathrm{er}}$ mai 1920) ", déjà cité. Le fonds de la seigneurie de Roucy avait été a cheté en 1908 par le Département de l'Aisne à Mme d'Imécourt, remariée en secondes noces au baron de Wangenheim, surintendant des théâtres du duché de Brunswick.

63. - Arch. nat., $\mathrm{AB} X X X \mathrm{XX} / 44$, circulaire du ministre de l'Instruction publique et des Beaux-Arts aux préfets, 26 novembre 1918. "Lorsque [ce travail considérable] sera terminé, on saura exactement ce qui a disparu ; à quelle date et dans quelle circonstances les disparitions ont eu lieu : les inventaires anciens et modernes, manuscrits et imprimés, qui peuvent donner, en quelque mesure, l'idée des fonds et des pièces détruites, seront en même temps indiqués » [Arch. nat., $\mathrm{AB}$ XXXI/15, « Rapport au ministre de l'Instruction publique et des Beaux-Arts sur le service des archives (1 ${ }^{\mathrm{er}}$ mai 1918- $1^{\mathrm{er}}$ mai 1919) ", déjà cité, p. 5954].

64. - Arch. nat., AB/XXXI/63-72 (/63 : Aisne, /64 : Ardennes, /65 : Marne, /66 : Meurthe-etMoselle, /67 : Meuse, /68 : Nord, /69 : Oise, /70 : Pas-de-Calais, /71 : Somme, /72 : Vosges).

65. - Arch. nat., $\mathrm{AB} / \mathrm{XXXI} / 66$, lettre du directeur des Archives départementales de Meurthe-etMoselle au directeur des Archives nationales, Nancy, 11 décembre 1918.

66. - Arch. nat., $\mathrm{AB} X X X \mathrm{XX} / 44$, circulaire du ministre de l'Instruction publique et des Beaux-Arts aux préfets, 13 décembre 1918.

67. - Arch. nat., $\mathrm{AB} / \mathrm{XXXI} / 66$, lettre du directeur des Archives départementales de Meurthe-etMoselle au directeur des Archives nationales, Nancy, 13 octobre 1919.

68. - Arch. nat., AB/XXXI/68, lettre du préfet du Nord au ministre de l'Instruction publique / direction des Archives nationales, 12 novembre 1919.

69. - Arch. nat., $\mathrm{AB} X X X \mathrm{XX} / 15$, « Rapport au ministre de l'Instruction publique et des Beaux-Arts sur le service des archives ( ${ }^{\mathrm{er}}$ mai 1919-1er mai 1920) », déjà cité. Le palais abbatial de SaintVaast d'Arras a été incendié le 5 juillet 1915.

70. - Le 25 mai 1915, Langlois avait écrit au ministre de l'Instruction publique : "Reste qu'il faut prévoir le retour de l'Alsace-Lorraine à la France et les conséquences de cet événement au point de vue du service. Il existe, sur les négociations entre la France et l'Allemagne au sujet des territoires annexés par l'Empire en 1871 et sur l'organisation actuelle des archives d'AlsaceLorraine, des moyens d'information abondants. Ils ont été réunis et étudiés par la direction des Archives dès le mois d'août 1914. Tout est prêt à cet égard. » [Arch. nat., AB XXXI/356, note du 25 mai 1915].

71. - Arch. nat., $A B X X X I / 15$, « Rapport au ministre de l"Instruction publique et des Beaux-Arts sur le service des archives (1 ${ }^{\text {er }}$ mai 1918- er $^{\text {er }}$ mi 1919) », déjà cité, p. 5954.

72. - Arch. nat., AB XXXI/358, « Projet » de Ch.-V. Langlois pour les archives d'Alsace et de Lorraine, [début 1919]. Au plan budgétaire, la direction des Archives devait donc nommer quatre 
personnes supplémentaires : à Strasbourg, un archiviste en chef pour l'Alsace et un archiviste adjoint spécialement chargé du Bas-Rhin, à Colmar, un archiviste départemental, à Metz, un archiviste départemental. Langlois envisageait également que l'École des chartes envoyât chaque année à Strasbourg un stagiaire s'initier au maniement des documents allemands.

73. - Arch. nat., $\mathrm{AB} X X X \mathrm{XX} / 15$, « Rapport au ministre de l'Instruction publique et des Beaux-Arts sur le service des archives ( $1^{\mathrm{er}}$ mai 1919-1er mai 1920) », déjà cité.

74. - Ibid. Langlois regrette que la solution belge n'ait pas été appliquée : « [Le traité] aurait pu stipuler, pour le préjudice causé de ce chef au patrimoine historique de la France, des compensations en nature, de l'espèce de celles qui ont été accordées, par l'article 246, à l'université de Louvain. Cela n'a pas été fait. Force est donc de s'en tenir à des demandes en compensation pécuniaire. "

75. - Arch. nat., $\mathrm{AB} / \mathrm{XXXI} / 73$.

76. - Arch. nat., $A B X X X I / 356$, procès-verbal de la réunion des archivistes des régions libérées, à Paris, le 25 janvier 1920, rassemblant les archivistes de l'Aisne (Broche), de la Marne (Berland), de Meurthe-et-Moselle (Duvernoy), du Nord (Bruchet), de l'Oise (Roussel), du Pas-de-Calais (Besnier), de la Somme (Estienne) et l'archiviste intérimaire de la Meuse. Ceux des Ardennes (Laurent) et des Vosges (Philippe) ne purent s'y rendre.

77. - Arch. nat., AB XXXI/75, circulaire du ministre de l'Instruction publique et des Beaux-Arts et du ministre des Régions libérées aux préfets des départements atteints par les événements de guerre relative à l'évaluation des archives publiques détruites pendant la guerre, 14 février 1920 . Afin de faciliter le calcul, un barême pour la copie de 126 années d'état civil (1793-1918) était proposé à l'appui, selon la population de la commune, ainsi que les exemples de l'estimation des réparations pour la sous-préfecture de Péronne et la commune d'Allaines.

78. - Arch. nat., $\mathrm{AB} X X X \mathrm{X} / 15$, « Rapport au ministre de l'Instruction publique et des BeauX-Arts sur le service des archives ( $1^{\mathrm{er}}$ mai 1919-1er mai 1920)», déjà cité.

79. - «L'attention de la Conférence a été appelée, notamment, sur ce point qu'il n'y a pas de prescription pour certains enlèvements abusifs pratiqués par les Allemands en 1870-1871, en particulier au préjudice des Archives départementales des Vosges " [Arch. nat., AB XXXI/15, « Rapport au ministre de l'Instruction publique et des Beaux-Arts sur le service des archives $\left(1^{\mathrm{er}}\right.$ mai 1918- ${ }^{\text {er }}$ mai 1919)», déjà cité, p. 5954].

80. - Sur le détail des communes annexées et les conditions de cette saisie, voir Guide des archives départementales des Vosges, sous la direction d'Isabelle Chave et de Marie-Astrid Zang. Épinal : Conseil général des Vosges, 2012, p. 15.

81. - $\mathrm{AB} X X X I / 356$, Ministère de l'Instruction publique. Premier mémoire à la commission des réparations, 31 octobre 1919.

82. - L'annexion de la principauté de Montbéliard à la France (décret du 10 octobre 1793) fut consacrée par le traité du 28 thermidor an IV entre la République et le duc de Wurtemberg, qui transférait au Domaine public français les archives de la principauté. Dès le VI brumaire an III, la Convention avait prescrit aux administrateurs du district de Montbéliard d'opérer le triage des titres contenus dans les différents dépôts, greffes et archives de l'ex-principauté, selon la loi du 7 messidor an II, organisant les archives de la République. Ce triage ne fut achevé qu'en 1840 ; les Archives départementales du Haut-Rhin reçurent quelques caisses de titres et surtout 20000 pièces du comté de Horbourg et de la seigneurie de Riquewihr, possessions en Alsace des princes wurtembergeois de Montbéliard. Le fonds de Montbéliard des Archives départementales du BasRhin, riche de 28000 titres vers 1860, avait une autre origine : en 1809, par entente entre Napoléon $\mathrm{I}^{\mathrm{er}}$ et le duc de Wurtemberg, les archives de la principauté de Montbéliard présentes à Ludwigsbourg furent partagées entre la France et le Wurtemberg ; les titres locaux et domaniaux en surplus furent remis à un diplomate qui, sur l'ordre du ministre, les expédia à Strasbourg, aux Archives départementales $[\mathrm{AB} \mathrm{XXXI} / 356$, Note sur les stipulations à insérer dans le traité de paix, en ce qui concerne les archives, [1919]]. 
83. - $\mathrm{AB} \mathrm{XXXI} / 356$, Ministère de l'Instruction publique. Premier mémoire à la commission des réparations, 31 octobre 1919.

84. - Arch. nat., AB XXXI/356, note [trad. en fr.] du colonel Von Muller, commission allemande d'armistice, au général Nudant, commission interalliée d'armistice, Spa, 21 mars 1919.

85. - Arch. nat., $A B X X X I / 356$, lettre de Pelissier, ingénieur hydrographe de la Marine, chef du groupe des canevas de tir de l'état-major de la $\mathrm{X}^{\mathrm{e}}$ Armée, à Dincher, chef de bataillon du $8^{\mathrm{e}}$ tirailleurs d'Afrique, attaché au commissariat de la République à la préfecture de Moselle, Grand Quartier général, 22 avril 1919.

86. - Arch. nat., AB XXXI/356, lettre de G. Rouvier, inspecteur général des services administratifs au ministère de l'Intérieur, à Mirman, commissaire de la République à Metz, Spa, 2 avril 1919.

87. - Arch. nat., $\mathrm{AB} X X X \mathrm{X} / 356$, lettre du ministre de l'Instruction publique au ministre des Régions libérées, Paris, 24 juin 1919.

88. - Arch. nat., $\mathrm{AB} X X X \mathrm{XX} / 15$, « Rapport au ministre de l'Instruction publique et des Beaux-Arts sur le service des archives (1 ${ }^{\mathrm{er}}$ mai 1919-1er mai 1920) ", déjà cité.

89. - [Arch. nat., AB XXXI/15, « Rapport au ministre de l'Instruction publique et des Beaux-Arts sur le service des archives ( $1^{\mathrm{er}}$ mai 1920- $1^{\mathrm{er}}$ mai 1921) ", par Charles-Victor Langlois, Journal officiel de la République française, 18 mai 1921].

90. - Guide des archives départementales des Vosges, ouvr. cité, p. 15-16.

91. - Arch. nat., AB XXXI/15, « Rapport au ministre de l'Instruction publique et des Beaux-Arts sur le service des archives (1 $1^{\mathrm{er}}$ mai 1918-1 ${ }^{\mathrm{er}}$ mai 1919) », déjà cité, p. 5954.

92. - Arch. nat., $A B X X X I / 358$, « Rapport sur une mission dans les territoires rhénans (18-31 janvier 1919) ", Paris, 4 février 1919.

93. - Arch. nat., $\mathrm{AB} X X X \mathrm{XX} / 358$, copie de la lettre du maréchal Foch au président du Conseil, ministre de la Guerre, Grand Quartier général, 10 mars 1919.

94. - Arch. nat., AB XXXI/358, copie d'une lettre du général Gérard, commandant la VIII ${ }^{\mathrm{e}}$ Armée, au maréchal Foch, commandant en chef les armées françaises, 4 mars 1919. Cet inventaire, mis en forme, fait d'ailleurs l'objet d'une édition imprimée en 1919, aux frais de la X ${ }^{\mathrm{e}}$ Armée : VIAL-MAZEL, G. (lieutenant). Inventaire analytique des fonds français conservés aux Archives de Spire, $\mathrm{VIII}^{\mathrm{e}}$ Armée, Armée d'occupation du Palatinat. Impr. du GCTA 8, 1919 [Arch. nat., AB XXXI/358].

95. - Arch. nat., $A B X X X I / 358$, lettre du directeur de l'Enseignement supérieur au directeur des Archives, [reçue le 21 mars 1919], jointe à l'inventaire des lettres et arrêtés du général Hoche conservés aux Archives d'État de Coblence.

96. - Arch. nat., $\mathrm{AB}$ XXXI/358, brouillon de lettre de Langlois à la direction de l'Enseignement supérieur, 18 juin 1919.

97. - Arch. nat., $\mathrm{AB} X X X \mathrm{XX} / 358$, « Rapport sur une mission dans les territoires rhénans (18-31 janvier 1919) ", déjà cité, p. 9-10.

98. - Arch. nat., $\mathrm{AB} / \mathrm{XXXI} / 3$, registre des séances de la Commission supérieure des Archives (1906-1933), séance du 26 juin 1919, p. 190.

99. - Arch. nat., AB XXXI/358, brouillon de lettre de Ch.-V. Langlois au contrôleur général de l'administration des Territoires rhénans, Paris, 8 juillet 1919.

100. - Arch. nat., AB XXXI/358, « Rapport sur une mission en Allemagne. 19 juillet-8 août 1919 ", par Ch. Schmidt, Paris, 13 août 1919, p. 8.

101. - Arch. nat., AB XXXI/358, lettre du commissaire de la République au directeur des Archives de France, Coblence, 29 août 1919.

102. - Les archives des directions des forêts, des domaines et des droits réunis, en revanche, ont été détruites presque totalement [Arch. nat., $\mathrm{AB}$ XXXI/358, « Rapport sur une mission dans les territoires rhénans (18-31 janvier 1919) ", déjà cité, p. 4].

103. - Dès le 29 juillet, Bär alerte le directeur des Archives des obstacles à la réalisation de tels inventaires (coût d'une mission de plusieurs semaines, accès à des magasins en partie fermés, opérations de désinfection préalables) et invite à confier à un militaire sachant l'allemand une 
simple copie des inventaires manuscrits existants [Arch. nat., AB XXXI/358, lettre du Dr Bär à Ch.-V. Langlois, Coblence, 29 juillet 1919].

104. - Arch. nat., AB XXXI/358, brouillon d'une lettre de Ch.-V. Langlois au Dr Bär, Paris, 14 août 1919.

105. - Arch. nat., AB XXXI/358, brouillon d'une lettre de Ch..-V. Langlois au Dr Bär, Paris, 11 octobre 1919, et lettre du commissaire de la République française, Commission interalliée des territoires rhénans, à Charles Schmidt, directeur des archives d'Alsace et de Lorraine, Coblence, 17 octobre 1919.

106. - Arch. nat., $\mathrm{AB} X X X \mathrm{XX} / 358$, « Rapport sur une mission dans les territoires rhénans (18-31 janvier 1919)", déjà cité, p. 4-5.

107. - La publication de l'inventaire sommaire de J. Estienne était prévue dans la Bibliographie moderne [Arch. nat., AB XXXI/358, « Rapport sur une mission en Allemagne. 19 juillet-8 août 1919 ", déjà cité, p. 5]. Un article intitulé « Archives des Villes du Palatinat. Note de service n 3227 du 4 mars 1919 » est ainsi publié dans le Bulletin de l'armée d'occupation du Palatinat, n¹1, 16 mars 1919, p. 186.

108. - Arch. nat., AB XXXI/358, « Rapport sur une mission dans les territoires rhénans (18-31 janvier 1919) ", déjà cité, p. 6 : archives du commissariat général à Kreuznach, puis Mayence, soit l'administration des territoires rhénans avant la division en départements; archives du département du Mont-Tonnerre, et notamment des arrondissements de Spire, des Deux-Ponts et de Kaiserslautern ; archives issues de l'échange entre Spire et Strasbourg de 1868, soit celles des communes des départements du Bas-Rhin et du Mont-Tonnerre cédées à l'Allemagne par les traités de 1814-1815, contre les archives des principautés de Ribeaupierre et de Hanau, cédées aux Archives départementales du Bas-Rhin.

109. - Arch. nat., AB XXXI/358, lettre de L. Royer à Charles-Victor Langlois, 4 juin 1919.

110. - Arch. nat., $A B X X X I / 358$, « Rapport sur une mission dans les territoires rhénans (18-31 janvier 1919) ", déjà cité, p. 5-6. En juillet 1919, ne pouvant s'y déplacer à nouveau, Schmidt demande au colonel Strohl d'envoyer également Font-Réaulx à Wiesbaden.

111. - Arch. nat., $\mathrm{AB} X X X \mathrm{X} / 356$, Note sur les stipulations à insérer dans le traité de paix, en ce qui concerne les archives, [1919].

112. - Arch. nat., $A B X X X I / 358$, minute de la lettre du ministre de l'Instruction publique au président du Conseil, ministre de la Guerre, 30 novembre 1918.

113. - Atlas « réclamé avec insistance par les Prussiens en 1815 » [Arch. nat., AB XXXI/358, « Rapport sur une mission dans les territoires rhénans (18-31 janvier 1919) », déjà cité, p. 7]. « C'est sans doute à Sarrebrück que se fera la centralisation de ces documents. Il y aura lieu, au moment du triage, de ne pas disloquer les fonds conservés à Coblence " [Ibid., « Rapport sur une mission en Allemagne. 19 juillet-8 août 1919 », déjà cité, p. 7].

114. - Arch. nat., AB XXXI/358, « Rapport sur une mission en Allemagne. 19 juillet-8 août 1919 », déjà cité, p. 6.

115. - Arch. nat., AB XXXI/358, « Rapport sur une mission en Allemagne. 19 juillet-8 août 1919 », déjà cité.

116. - « Il faut que l'exemple donné par l'Allemagne ne soit pas perdu pour la France et l'on souhaiterait que le premier dépôt d'archives économiques français fût organisé à Strasbourg, au centre de cette région alsacienne et lorraine dont le développement économique a été si considérable depuis cinquante ans " [Arch. nat., AB XXXI/358, "Rapport sur une mission en Allemagne. 19 juillet-8 août 1919 ", déjà cité]. Ce dépôt d'archives, créé à Cologne en 1806 pour collecter les archives des particuliers (commerçants, industriels, financiers de la région rhénane), de sociétés par actions, de compagnies de chemins de fer, de chambres de commerce, etc., avait été imité depuis à Bruxelles, à Bâle et dans d'autres villes allemandes. Schmidt en avait revélé l'intérêt dès avant la guerre, y consacrant un article dans la Bibliographie moderne, 1911, n³-4. 
117. - Arch. nat., $A B$ XXXI/358, « Rapport sur une mission en Allemagne. 19 juillet-8 août 1919 », déjà cité.

118. - Elle est d'ailleurs citée par le député Claude Cochin dans son article « Les archives et la guerre » [La Revue hebdomadaire et son supplément illustré, n²7, 7 juillet 1917, p. 66], pourtant peu enclin à reconnaître l'efficacité de l'administration de son temps.

119. - Arch. nat., AB XXXI/34, projets de loi et loi publiée au JO du 16 décembre 1923, 2 mars 1920-16 décembre 1923.

120. - COCHIN, Claude. "Les archives et la guerre », art. cité, p. 64-75 (p. 70) [Arch. nat., AB $\mathrm{XXXI} / 24]$.

121. - Dans la Seine, en 1914, « le Service a déjà reçu, sur sa demande, la liste des réfugiés et celle des rapatriés d'Allemagne " [Marius Barroux, "Rapports annuels de l'archiviste [de la Seine]. Exercices 1913-1914 et 1914-1915 », déjà cité, p. 4]. En novembre 1918, il signale aussi avoir récupéré « une liasse provenant du bureau de l'Approvisionnement et qui contient des refus de meuniers et des lettres de boulangers de 1916 et 1917 ; puis les dossiers de l'ancien fichier du sucre du XVII ${ }^{\mathrm{e}}$ arrondissement (150 liasses) » et regrette que les citations n'aient pas été systématiquement compilées : "Il aurait été, semble-t-il, intéressant de recueillir, pour en former collection, les notes relatives aux citations qu'ont obtenues des soldats de la région parisienne et publiées dans le Bulletin municipal.» [Ibid., p. 29].

122. - Arch. nat., $\mathrm{AB} X X X \mathrm{X} / 44$, circulaire du ministre de l'Instruction publique et des BeauX-Arts aux préfets relative au classement des papiers de la censure, 24 octobre 1917 [à classer dans la série $\mathrm{M}$ affectée aux dossiers de la Police générale et administrative].

123. - Arch. nat., $\mathrm{AB} X X X \mathrm{X} / 44$ et $/ 73$.

124. - Arch. nat., $\mathrm{AB} X X X \mathrm{X} / 44$, circulaire du ministre de l'Instruction publique et des BeauX-Arts aux préfets, 15 avril 1922.

125. - Arch.nat., AB/XXXI, 73. HUBERT, Jean. Classement et conservation des archives des divers services créés à l'occasion de la guerre de 1914-1918: réponses faites par les archivistes départementaux aux circulaires du 8 octobre 1919 et 31 octobre 1928. Melun, $1^{\mathrm{er}}$ mars 1939, 41 p. dactyl.

126. - Arch. nat., AB/XXXI/73.

127. - I. Papiers existants dans la plupart des services. - A. Correspondance générale (demandes de renseignements, affaires diverses, après tri). - B. Comptabilité (livres journaux, sauf les grands livres ; livres de caisses, livres auxiliaires, pièces justificatives de dépenses : mémoires, factures, bulletins de livraison, etc. ; états périodiques de situation des crédits, de situation de caisse, de mandats émis ; accusé de réception des mandats). - C. Transports (carnets à souches d'ordres de transport, demandes de transport gratuit : personnel et matériel ; transports par priorité, lettres de voitures, récépissés de chemin de fer, bulletins de chargement et de conduite, avis d'expédition, relevés d'expéditions et de transport, location de wagons). II. Services particuliers.- A. Fonctionnaires (allocations temporaires aux petits retraités, sauf les états; suppléments de traitement). - B. Ravitaillement (services préfectoraux, bureaux permanents des céréales, offices départementaux du charbon, etc.): personnel (états d'émargement, frais de déplacement, indemnités aux secrétaires de mairie), états périodiques (situation journalière des grains, situations hebdomadaires, décadaires des moulins), demandes de blé, de seigle, de farine, de sucre, de charbon, d'essence, etc. ; demandes de charbon et d'essence pour le battage, carnets d'achat, carnets de permis de circulation, factures en magasin ; ordres de livraison, permis d'expédition ; ristourne à la charge des minotiers, carnets et feuilles de tickets de rationnement ; bons de pain à prix réduit, listes des bénéficiaires ; mouvement des cartes d'alimentation, distribution des cartes et des carnets (demandes des municipalités, bordereaux d'envoi), incinération des bons de pain, sacherie (sauf instructions, affaires générales, renseignements sur les prêts et les lieux de provenance des emballages, états statistiques), essence (bons de réapprovisionne-ment et de consommation). - C. Étrangers (fiches individuelles, camps de concentration : pièces relatives à l'entretien et à l'alimentation des internés). - D. Réfugiés (états 
mensuels des arrivées et des départs, fiches individuelles, états d'allocations et de secours divers, secours en nature : facture des fournisseurs ; soins médicaux : mémoires des médecins, sagesfemmes, pharmaciens ; mesures diverses d'assistance). - E. Affaires militaires (exemptés et réformés : pièces médicales, après 30 ans ; sursis pour les pères de familles nombreuses, les ouvriers agricoles, les boulangers et autres professions ; permissions de moisson et de vendange ; prisonniers de guerre : fiches individuelles, si relevés collectifs ; correspondance, après tri ; factures d'achat des vêtements, tricots et autres objets envoyés aux prisonniers ; diplômes non réclamés des soldats morts pour la France. III. Documents dont la suppression pourra être envisagée après triage très soigné, à partir de 1950. - Commissions arbitrales des loyers, dommages de guerre. 128. - BARROUX, Marius. « Rapports annuels de l'archiviste [de la Seine]. Exercices 1913-1914 et 1914-1915 ", déjà cité, p. 15.

\section{RÉSUMÉS}

La guerre de 1914-1918 a marqué les services d'archives en France comme les autres institutions culturelles. À travers le fonds d'archives de la direction ministérielle des Archives et les études consacrées aux départements du nord-est de la France, le sort du patrimoine archivistique durant cette période est aujourd'hui mieux connu: destructions majeures et ciblées, sélection des fonds à protéger et à évacuer vers des zones-refuge loin du front, tournées territoriales d'inspection et de recensement documentaire, donnent à voir l'implication concrète des archivistes, la mise en place de véritables plans d'urgence, des réponses ciblées à une situation de crise exceptionnelle, souvent dans le souvenir des pertes déjà subies lors de la guerre francoprussienne de 1870 . Cette mémoire des conflits successifs s'illustre particulièrement dans les négociations de l'immédiat après-guerre, lorsqu'il s'agit de faire reconnaître, par les réparations, les revendications ou une politique de reconstitution documentaire, l'ampleur $\mathrm{du}$ choc patrimonial subi.

The First World War had a considerable impact on French archive services, as it did on other cultural institutions. Looking at the papers held today by the ministerial archival directorate (direction ministérielle des Archives) and at some local studies concentrating on the departments situated in the North-East of France, it is possible today to have a better understanding of what became of this paper heritage during the war years. As is to be seen in examples of major and selective programs of destruction, in the choice of which holdings were to be protected and evacuated to safety far from the front line, and in territorial tours of inspection and documentation, French archivists were directly implicated in establishing contingency procedures and appropriate responses to the situation of exceptional crisis, often inspired by memories of archives lost during the Franco-Prussian of 1870. This on-going memory of successive conflicts is particularly to be noted in the negotiations of the immediate post-war years: by means of war reparations or by the reconstitution of documentary collections, what was at stake was the recognition of the importance of the damage suffered by heritage. 


\section{INDEX}

Mots-clés : affiches de la Grande Guerre, annexion allemande, archives départementales, archives des services de guerre, archives françaises des dépôts rhénans, Archives nationales de France, archivistes des régions libérées, commission allemande d'armistice, commission interalliée permanente d'armistice, Commission supérieure des archives, destruction patrimoniale, évacuations patrimoniales, guerre franco-prussienne de 1870, histoire des archives, musée de la Guerre, occupation napoléonienne, patrimoine archivistique, plan d'urgence patrimonial, reconstitution d'archives, réparations, restitutions d'archives, revendications patrimoniales, traité de Versailles, Camille BLOCH, Charles-Victor LANGLOIS, Henri LEBLANC, Charles SCHMIDT

\section{AUTEUR}

\section{ISABELLE CHAVE}

Conservateur en chef du patrimoine, Archives nationales, Responsable du département Exécutif et Législatif (DEL) isabelle.chave@culture.gouv.fr 